NBER WORKING PAPER SERIES

\title{
QUANTIFYING LIQUIDITY AND DEFAULT RISKS OF CORPORATE BONDS OVER THE BUSINESS CYCLE
}

\author{
Hui Chen \\ Rui Cui \\ Zhiguo He \\ Konstantin Milbradt \\ Working Paper 20638 \\ http://www.nber.org/papers/w20638 \\ NATIONAL BUREAU OF ECONOMIC RESEARCH \\ 1050 Massachusetts Avenue \\ Cambridge, MA 02138 \\ October 2014
}

We thank Ron Anderson, Mark Carey, Pierre Collin-Dufresne, Thomas Dangl, Vyacheslav Fos, Joao Gomes, Lars Hansen, Jingzhi Huang, David Lando, Mads Stenbo Nielsen, Martin Schneider, and seminar participants at Chicago economic dynamics working group, ECB, Georgia Tech, Kellogg, Maryland, MIT Sloan, the NBER Summer Institute (Risk of Financial Institution, Capital Markets), Federal Reserve Board, AFA 2014, the USC Fixed Income Conference, University of Alberta, University of Calgary, Central European University, Wirtschaftsuniversitaet Wien, WFA, CICF, the Rothschild Caesarea Conference, and the Stanford Institute for Theoretical Economics Workshop for helpful comments. We acknowledge the financial supported from the Fama-Miller Center at Booth School of Business, University of Chicago. The views expressed herein are those of the authors and do not necessarily reflect the views of the National Bureau of Economic Research.

NBER working papers are circulated for discussion and comment purposes. They have not been peerreviewed or been subject to the review by the NBER Board of Directors that accompanies official NBER publications.

(C) 2014 by Hui Chen, Rui Cui, Zhiguo He, and Konstantin Milbradt. All rights reserved. Short sections of text, not to exceed two paragraphs, may be quoted without explicit permission provided that full credit, including $\odot$ notice, is given to the source. 
Quantifying Liquidity and Default Risks of Corporate Bonds over the Business Cycle Hui Chen, Rui Cui, Zhiguo He, and Konstantin Milbradt

NBER Working Paper No. 20638

October 2014

JEL No. G00,G1,G12,G20

\begin{abstract}
$\underline{\text { ABSTRACT }}$
We develop a structural credit risk model to examine how the interactions of liquidity and default risk affect corporate bond pricing. By explicitly modeling debt rollover and by endogenizing the holding costs via collateralized financing, our model generates rich links between liquidity risk and default risk. The introduction of macroeconomic risks helps the model capture realistic time variation in default risk premia and the default-liquidity spiral over the business cycle. Across different credit ratings, our calibrated model can simultaneously match the average default probabilities, credit spreads, and bond liquidity measures including Bond-CDS spreads and bid-ask spreads in the data. Through a structural decomposition, we show that the interactions between liquidity and default risk account for $2540 \%$ of the observed credit spreads and up to $55 \%$ of the credit spread changes over the business cycle. As an application, we use this framework to quantitatively evaluate the effects of liquidity-provision policies for the corporate bond market.
\end{abstract}

Hui Chen

MIT Sloan School of Management

100 Main Street, E62-637

Cambridge, MA 02142

and NBER

huichen@mit.edu

Rui Cui

University of Chicago

ruicui1@gmail.com
Zhiguo He

University of Chicago

Booth School of Business

5807 S. Woodlawn Avenue

Chicago, IL 60637

and NBER

zhiguo.he@chicagobooth.edu

Konstantin Milbradt

Kellogg School of Management

Northwestern University

2001 Sheridan Rd \#401

Evanston, IL 60208

and NBER

milbradt@northwestern.edu 


\section{Introduction}

It is well known that a significant part of corporate bond pricing cannot be accounted for by default risk alone. For example, Longstaff, Mithal, and Neis (2005) estimate that "non-default components" account for about $50 \%$ of the spread between the yields of Aaa/Aarated corporate bonds and Treasuries and about 30\% of the spread for Baa-rated bonds. Furthermore, Longstaff, Mithal, and Neis (2005) find that non-default components of credit spreads are strongly related to measures of bond liquidity, which is consistent with evidence of illiquidity in secondary corporate bond markets (e.g., Edwards, Harris, and Piwowar (2007), Bao, Pan, and Wang (2011)).

Hitherto, the literature on structural credit risk modeling has almost exclusively focused on the "default component" of credit spreads. The "credit spread puzzle," as defined by Huang and Huang (2012), refers to the finding that, after matching the observed default and recovery rates, traditional structural models produce credit spreads for investment grade bonds that are significantly lower than those in the data. By introducing macroeconomic risks into structural credit models, Chen, Collin-Dufresne, and Goldstein (2009), Bhamra, Kuehn, and Strebulaev (2010) and Chen (2010) are able to explain the default components of the credit spreads for investment-grade bonds. ${ }^{1}$ However, these models are silent on the sources of the non-default component of credit spreads and their potential impact on the default component of the spreads.

In this paper, we build a tractable structural credit risk model that captures both the default and non-default components in corporate bond pricing by introducing secondary market search frictions (a la Duffie, Gârleanu, and Pedersen (2005)) into a model with aggregate macroeconomic fluctuations (e.g., Chen (2010)). Rather than simply piecing

\footnotetext{
${ }^{1}$ Chen (2010) relies on estimates of Longstaff, Mithal, and Neis (2005) to obtain the default component of the credit spread for Baa rated bonds, while Bhamra, Kuehn, and Strebulaev (2010) focus on the difference between Baa and Aaa rated bonds. The difference of spreads between Baa and Aaa rated bonds presumably takes out the common liquidity component, which is a widely used practice in the literature. This treatment relies on the assumption that the liquidity components for bonds of different ratings are the same, which is at odds with existing literatures on the liquidity of corporate bonds, e.g., Edwards, Harris, and Piwowar (2007), Bao, Pan, and Wang (2011).
} 
together the default and non-default components of credit spreads, our approach of jointly modeling default and liquidity risk over the business cycle is essential to understanding the interactions between the two components. Such interactions give rise to endogenous default as well as endogenous liquidity, which helps explain two general empirical patterns for the liquidity of corporate bonds: (1) corporate bonds with higher credit ratings tend to be more liquid; (2) corporate bonds are less liquid during economic downturns, especially for riskier bonds. ${ }^{2}$ These interactions can also significantly raise the level of credit spreads and make them more volatile over the business cycle.

In our model, which builds on He and Milbradt (2014), investors face uninsurable idiosyncratic liquidity shocks, which drive up their costs for holding corporate bonds. Market illiquidity arises endogenously because to sell their bonds, investors have to search for dealers to intermediate transactions with other investors not yet hit by liquidity shocks, and in the meantime they incur costs for having to hold onto the bonds. The dealers set bid-ask spreads to capture part of the trading surplus. On the one hand, default risk crucially affects the trading surplus and thus the liquidity discount of corporate bonds. On the other hand, heavier liquidity discount makes it more costly for firms to roll over their maturing debt, hence raising the probability of default. Thus, a default-liquidity spiral arises: when secondary market liquidity deteriorates, equity holders are more likely to default, which in turn worsens secondary bond market liquidity even further, and so on so forth.

Our model extends He and Milbradt (2014) in two important aspects. First, instead of assuming a constant exogenous holding cost due to liquidity shocks as in He and Milbradt (2014), we model holding costs based on the mechanism of collateralized financing. In this mechanism, investors hit by liquidity shocks raise cash either via cheaper collateralized financing (with the bond as collateral, subject to some haircuts) or more expensive uncollateralized financing. A lower bond market price together with a larger haircut pushes investors toward more expensive uncollateralized financing, which translates to higher effective holding costs

\footnotetext{
${ }^{2}$ See e.g., Edwards, Harris, and Piwowar (2007), Bao, Pan, and Wang (2011), Dick-Nielsen, Feldhütter, and Lando (2012), and Friewald, Jankowitsch, and Subrahmanyam (2012).
} 
for bonds with higher default risk.

Second, our paper introduces aggregate macroeconomics states as in Chen (2010) into He and Milbradt (2014) by explicitly modeling the procyclical liquidity together with cyclical variations in the firm's cash flows and aggregate risk prices. This allows us to generate significant time variation in default risk premia, an essential feature of the data. Moreover, it generates a liquidity risk premium in corporate bond pricing since secondary market liquidity worsens (e.g., the meeting intensity with dealers decreases) in recessions when investors' marginal utilities are high. Together, these two types of risk premia magnify the quantitative effect of the default-liquidity spiral over the business cycle.

We follow the literature to set the pricing kernel parameters over two macroeconomic states (economic expansions and recessions) to fit a set of standard moments of asset prices. The parameters governing secondary bond market liquidity over macroeconomic states are either pre-fixed based on existing empirical studies and TRACE data (e.g., bond turnover), or calibrated to match the moments that our model aims to explain (e.g., bid-ask spreads). We then apply our model with the same set of parameters to corporate bonds across four credit rating classes (Aaa/Aa, A, Baa, and Ba) and two different maturities (5 and 10 years). Altogether, we only calibrate four free parameters, a much lower degree of freedom relative to the number of moments that our model tries to explain.

To evaluate model performance, we not only examine the cumulative default probabilities and credit spreads - two common measures that the literature on corporate bond pricing has focused on-but also consider two empirical measures of non-default risk in corporate bonds. The first measure is the Bond-CDS spread, defined as the bond's credit spread minus the Credit Default Swap (CDS) spread on the same bond. This measure is motivated by Longstaff, Mithal, and Neis (2005), who argue that CDS prices mostly reflect the default risk because of their relatively liquid secondary market. The second measure is the bid-ask spread. These two measures crucially rely on secondary market illiquidity: in a model with a perfectly liquid bond market, both the implied Bond-CDS spread and bid-ask spread are zero. This approach differs from He and Milbradt (2014), whose calibration only matches the 
unconditional moments of credit spreads and bid-ask spreads, eschewing matching historic default rates or state-dependent moments of pricing and liquidity measures.

As it is well-known that the CDS market is the most liquid for 5-year contracts, our calibration focuses predominantly on bonds with 5-year maturity. The endogenous liquidity helps our calibrated model match closely the empirical patterns of default probabilities and credit spreads for 5-year bonds both cross-sectionally (across credit ratings) and over time (across the business cycle). ${ }^{3}$ For non-default risk, the endogenous link between bond liquidity and a firm's distance-to-default allows us to generate the cross-sectional and business-cycle patterns observed in the date for both Bond-CDS spreads and bid-ask spreads. Overall, our model produces quantitatively reasonable non-default risk for corporate bonds. Relative to the data, our model can explain about $55 \%$ of observed variation in Bond-CDS spreads across rating classes, and future research incorporating heterogeneity of investor bases should further improve in this regard. The model's performance on 10-year bonds is less satisfactory: in comparison to the data, our model features a too steep term structure of credit spreads and Bond-CDS spreads.

It is common practice in the empirical literature to decompose credit spreads into a liquidity and a default component, with the interpretation that these components are independent of each other. Our model suggests that both liquidity and default are inextricably linked. Such dynamic interactions are difficult to capture using reduced-form models with exogenously imposed default and liquidity risk components. ${ }^{4}$

To quantify the interaction between default and liquidity, we propose a structural decomposition of credit spreads that nests the common additive default-liquidity decomposition. Motivated by Longstaff, Mithal, and Neis (2005) who use CDS spread to proxy for default risk, we identify the "default" component in the total credit spreads of a corporate bond by pricing the same bond in a hypothetical perfectly liquid market but using the default threshold

\footnotetext{
${ }^{3}$ Our calibration on aggregate macroeconomic states focuses on normal expansions and recessions, but not crises. As a result, in constructing empirical moments for recessions, we exclude the 2008 crises period from October (Q4) 2008 to March (Q1) 2009 throughout.

${ }^{4}$ See, for example, Duffie and Singleton (1999) and Liu, Longstaff, and Mandell (2006).
} 
endogenously derived from the full model with liquidity frictions. After subtracting this "default" component, we identify the remaining credit spread as the "liquidity" component.

We further decompose the "default" component into a "pure default" component and a "liquidity-driven-default" component, and the "liquidity" component into a "pure liquidity" component and a "default-driven liquidity" component. The "pure default" component is the spread for the same bond in a hypothetical setting where the bond market is perfectly liquid as in Leland and Toft (1996) and hence equity holders optimally choose to default less often. The "pure liquidity" component is the spread for default-free bonds when there are over-the-counter search frictions as in Duffie, Gârleanu, and Pedersen (2005). The two interaction terms, i.e., the "liquidity-driven default" and the "default-driven liquidity" component, capture the endogenous positive spiral between default and liquidity. For instance, "liquidity-driven-default" is driven by the rollover risk mechanism (He and Xiong (2012b)) in that firms relying on finite-maturity debt financing will default earlier when facing worsening secondary market liquidity.

We find that these interaction terms are quantitatively significant across all ratings. These interaction terms account for 25\% 30\% of the total credit spread of Aaa/Aa rated bonds and $35 \% \sim 40 \%$ of the total spread of Ba rated bonds across the two aggregate states. They account for $27 \%$ of the spread increase for Aaa/Aa rated bonds and $55 \%$ of the spread increase for Ba rated bonds as the economy switches from a normal state into a recession. We further perform a time-series default-liquidity decomposition for each rating category. Future studies can readily apply our decomposition scheme to individual firms.

By taking into account how individual firms' default decisions responds to changes in liquidity conditions, our model offers important new insight on evaluating the effectiveness of government policies that aim at improving market liquidity. Imagine a policy that improves the secondary market liquidity in a recession to the level of normal times. In our model, such a policy would lower the credit spread of Ba rated bonds in recession by about 112 bps, or $32 \%$ of the original spread. Furthermore, according to our decomposition, the policy's impact on the pure liquidity component only explains $23 \%$ of this reduction in credit 
spreads. In contrast, the liquidity-driven default component, which reflects the reduction in default risk when firms face smaller rollover losses, accounts for $67 \%$ of the reduction in the spread. The default-driven liquidity component, which captures the endogenous reduction of liquidity premium for safer bonds, explains the remainder, about 11\%. The prevailing view in the literature masks this interdependence between default and liquidity and thus could substantially under-estimate the impact of such liquidity policies.

Finally, the interconnection between liquidity and default also has important implications for an ongoing debate in accounting regarding how one should recognize losses on financial assets. ${ }^{5}$ Our model suggests that (il)liquidity can affect the credit losses for these debt instruments. Moreover, it offers a framework on how to use the liquidity information to evaluate the expected credit losses, which will help improve the accuracy of accounting for credit losses in debt instruments.

The paper is structured as follows. Section 2 introduces the model, which is solved in Section 3. Section 4 presents the main calibration. Section 5 discusses the model-based default-liquidity decomposition and its applications. Section 6 concludes.

\section{The Model}

Based on He and Milbradt (2014), we introduce secondary over-the-counter market search frictions (a la Duffie, Gârleanu, and Pedersen (2005)) into a structural credit risk Leland-type model with aggregate macroeconomic fluctuations. Our model extends He and Milbradt (2014) in two important aspects. First, we explicitly model aggregate shocks where firm cash flows and secondary market liquidity are procyclical while risk prices are countercyclical, which allows us to study the default-liquidity spiral across the business cycle. Second, instead of assuming constant holding costs for investors hit by liquidity shocks as in He and Milbradt (2014), we derive holding costs that decrease with bond prices through the mechanism of

\footnotetext{
${ }^{5}$ For instance, after the collapse of Asset-Backed-Securities market during the second half of 2007, the discussion focused on the interplay between default and liquidity and their respective accounting recognitions, e.g., being recognized as net income vs. comprehensive income.
} 
collateralized financing.

\subsection{Aggregate States and the Firm}

The following model elements are similar to Chen (2010), except that we introduce bonds with an average finite maturity a la Leland (1998) so that rollover risk is present.

\subsubsection{Aggregate states and stochastic discount factor}

The aggregate state of the economy is described by a continuous time Markov chain, with the current Markov state denoted by $s_{t}$ and the physical transition density between state $i$ and state $j$ denoted by $\zeta_{i j}^{\mathcal{P}}$. We assume an exogenous stochastic discount factor (SDF): ${ }^{6}$

$$
\frac{d \Lambda_{t}}{\Lambda_{t}}=-r\left(s_{t}\right) d t-\eta\left(s_{t}\right) d Z_{t}^{m}+\sum_{s_{t} \neq s_{t^{-}}}\left(e^{\kappa\left(s_{t^{-}}, s_{t}\right)}-1\right) d M_{t}^{\left(s_{t^{-}}, s_{t}\right)}
$$

where $Z_{t}^{m}$ is a standard Brownian Motion under the physical probability measure $\mathcal{P}, \eta(\cdot)$ is the state-dependent price of risk for aggregate Brownian shocks, $d M_{t}^{(j, k)}$ is a compensated Poison process capturing switches between states $i$ and $j$, and $\kappa(i, j)$ represents the jump risk premia such that the jump intensity between states $i$ and $j$ under the risk neutral measure $\mathcal{Q}$ is $\zeta_{i j}^{\mathcal{Q}}=e^{\kappa(i, j)} \zeta_{i j}^{\mathcal{P}}$. We focus on the case of binary aggregate states to capture the notion of economic expansions and recessions, i.e., $s_{t} \in\{G, B\}$. In the Internet Appendix we provide the general setup for the case of $n>2$ aggregate states.

Later on, we will introduce undiversifiable idiosyncratic liquidity shocks to investors. Upon receiving a liquidity shock, an investor who cannot sell the bond will incur a positive holding cost. In the presence of such liquidity shocks, bond investors can still price assets using the SDF in (1) provided that the bond holdings only make up an infinitesimal part of the representative investor's portfolio. ${ }^{7}$

\footnotetext{
${ }^{6}$ We adopt a partial equilibrium approach where the pricing kernel is exogenous. For general equilibrium credit risk models with endogenous pricing kernel, see, e.g., Gomes and Schmid (2010).

${ }^{7}$ Intuitively, if the representative agent's consumption pattern is not affected by the idiosyncratic shock
} 


\subsubsection{Firm cash flows and risk neutral measure}

A firm has assets in place that generate cash flows at the rate of $Y_{t}$. Under the physical measure $\mathcal{P}$, the cash-flow rate $Y_{t}$ dynamics, given the aggregate state $s_{t}$, are

$$
\frac{d Y_{t}}{Y_{t}}=\mu_{\mathcal{P}}\left(s_{t}\right) d t+\sigma_{m}\left(s_{t}\right) d Z_{t}^{m}+\sigma_{f} d Z_{t}^{f} .
$$

Here, $d Z_{t}^{m}$ captures aggregate Brownian risk, while $d Z_{t}^{f}$ captures idiosyncratic Brownian risk. Note that this is a nominal model as we do not specify a separate inflation process.

Given the stochastic discount factor $\Lambda_{t}$, the cash-flow dynamics under $\mathcal{Q}$ are

$$
\frac{d Y_{t}}{Y_{t}}=\mu_{\mathcal{Q}}\left(s_{t}\right) d t+\sigma\left(s_{t}\right) d Z_{t}^{\mathcal{Q}}
$$

where $Z_{t}^{\mathcal{Q}}$ is a standard Brownian Motion under $\mathcal{Q}$. The state-dependent risk-neutral growth rate and volatility of cash flows are given by

$$
\mu_{\mathcal{Q}}\left(s_{t}\right) \equiv \mu_{\mathcal{P}}\left(s_{t}\right)-\sigma_{m}\left(s_{t}\right) \eta\left(s_{t}\right), \text { and } \sigma\left(s_{t}\right) \equiv \sqrt{\sigma_{m}^{2}\left(s_{t}\right)+\sigma_{f}^{2}} .
$$

For the ease of notation, we work with $\log$ cash flows $y \equiv \log (Y)$ and denote the state dependence of the parameters using either a subscript or a superscript. Since we will work under $\mathcal{Q}$-measure unless otherwise stated, we drop the subscript $\mathcal{Q}$ where no confusion can arise. For instance, the risk-neutral dynamics of log cash flows are simply given by

$$
d y_{t}=\mu_{s} d t+\sigma_{s} d Z_{t}^{\mathcal{Q}}
$$

where

$$
\mu_{s} \equiv \mu_{\mathcal{Q}}\left(s_{t}\right)-\frac{1}{2} \sigma^{2}\left(s_{t}\right)=\mu_{\mathcal{P}}\left(s_{t}\right)-\sigma_{m}\left(s_{t}\right) \eta\left(s_{t}\right)-\frac{1}{2}\left[\sigma_{m}^{2}\left(s_{t}\right)+\sigma_{f}^{2}\right], \quad \sigma_{s} \equiv \sigma\left(s_{t}\right) .
$$

(which is true if the bond holding is infinitesimal relative to the rest of the portfolio), then the representative agent's pricing kernel is independent of the idiosyncratic undiversified shocks. 
We can obtain valuations for any asset by discounting the expected cash flows under the risk neutral measure $\mathcal{Q}$ with the risk-free rate. The unlevered firm value given the aggregate state $s$ and the cash-flow rate $Y$ is $v_{U}^{s} Y_{t}$, where the vector of price-dividend ratios $\mathbf{v}_{U}$ is

$$
\mathbf{v}_{U}=\left[\begin{array}{cc}
r_{G}-\mu_{G}+\zeta_{G} & -\zeta_{G} \\
-\zeta_{B} & r_{B}-\mu_{B}+\zeta_{B}
\end{array}\right]^{-1} \mathbf{1}
$$

\subsubsection{Firm's debt maturity structure and rollover frequency}

The firm has a unit measure of bonds in place that are identical except for their time to maturity, with the aggregate and individual bond coupon and face value being $c$ and $p$. As in Leland (1998), equity holders commit to keeping the aggregate coupon and outstanding face value constant before default, and thus issue new bonds of the same average maturity as the bonds maturing. We assume that the issuance of new bonds in the primary market incurs a proportional cost $\omega \in(0,1)$. Each bond matures with intensity $m$, and the maturity event is i.i.d. across individual bonds. Thus, by law of large numbers over $[t, t+d t)$ the firm retires a fraction $m \cdot d t$ of its bonds. This implies an expected average debt maturity of $\frac{1}{m}$. The deeper implication of this assumption is that the firm adopts a "smooth" debt maturity structure with an average refinancing/rollover frequency of $m$.

\subsection{Secondary Over-the-Counter Corporate Bond Market}

We follow Duffie, Gârleanu, and Pedersen (2005) and He and Milbradt (2014) to model the over-the-counter corporate bond market. All trades have to be intermediated through dealers. Bond investors can hold either zero or one unit of the bond. They start in the $H$ state without any holding cost when purchasing corporate bonds in the primary market. As time passes by, $H$-type bond holders are hit by idiosyncratic liquidity shocks with intensity $\xi_{s}$. These liquidity shocks lead them to become $L$-types who bear a positive holding cost $h c_{s}$ per unit of time, which we micro-found shortly. 


\subsubsection{Endogenous Holding Cost}

Different from He and Milbradt (2014) which features no aggregate state switching and constant holding cost equal to some exogenous constant, we have state-dependent holding $\operatorname{costs} h c^{s}\left(P^{s}\right)$ that depend on the prevailing bond prices as follows:

$$
h c_{s}\left(P^{s}\right)=\chi_{s}\left(N-P^{s}(y)\right)
$$

where $N>0, \chi_{s}>0$ are constants and $P^{s}(y)$ is the endogenous market price of the bond (to be derived in the next section).

In Appendix A, we provide a micro-foundation for (5) based on collateralized financing. We interpret a liquidity shock as the urgent need for an investor to raise cash which exceeds the value of all the liquid assets that he holds, a common phenomenon in modern financial institutions. Bond investors first use their bond holdings as collateral to raise collateralized financing at the risk-free rate subject to a haircut until they manage to sell the bonds; any remaining gap must be financed through uncollateralized financing, which requires a higher interest rate. In this setting, the investor obtains less collateralized financing if (i) the current market price of the bond is lower, and/or (ii) the haircut for the bond is higher. In practice, (i) and (ii) often coincide, with the haircut increasing while the price goes down. The investor's effective holding cost is then given by the additional uncollateralized financing cost, which increases when the bond price goes down. Under certain functional form assumptions on haircuts detailed in Appendix A, the holding cost takes the linear form in (5).

In Equation (5), at issuance the bond is priced at par value $p$, implying a baseline holding cost of $\chi_{s}(N-p)$ (we will set $N \geq p$ ). With $\chi_{s}>0$, the holding cost increases as the firm moves closer to default, so that the bond market value $P^{s}(y)$ goes down. This is the key channel through which our model captures the empirical pattern that lower rated bonds have worse secondary market liquidity.

The holding cost $h c_{s}\left(P^{s}\right)$ in (5) also depends on the aggregate state, through the following two channels. First, there is a direct effect, as we set $\chi_{B}>\chi_{G}$, which can be justified by the 
fact that the wedge between the collateralized and uncollateralized borrowing rates is higher in bad times. Second, there is an indirect effect, as the bond value $P^{s}(y)$ drops in bad times, giving rise to a higher holding cost. In Section 4.6 we study the quantitative importance of linking holding costs to firm's distant-to-default.

While we provide one micro-foundation for $h c_{s}\left(P^{s}\right)$ based on collateralized financing, there are other mechanisms via which institutional investors hit by liquidity shock incur extra losses if the market value of their bond holdings has dropped. For instance, suppose that corporate bond fund managers face some unexpected withdrawals when hit by a liquidity shock. As models with either learning managerial skills or coordination-driven runs would suggest, the deteriorating bond portfolios can trigger even greater fund outflows and extra liquidation costs. ${ }^{8}$

\subsubsection{Dealers and Equilibrium Prices}

There is a trading friction in moving the bonds from $L$-type sellers to $H$-type potential buyers currently not holding the bond in that trades have to be intermediated by dealers in the over-the-counter market. Sellers meet dealers with intensity $\lambda_{s}$, which we interpret as the intermediation intensity of the bond market. For simplicity, we assume that after $L$-type investors sell their holdings, they exit the market forever. ${ }^{9}$ The $H$-type buyers on the sideline currently not holding the bond also contact dealers with intensity $\lambda_{s}$. We follow Duffie, Gârleanu, and Pedersen (2007) to assume Nash-bargaining weights $\beta$ for the investor and $1-\beta$ for the dealer, constant across all dealer-investor pairs and aggregate states.

Dealers use the competitive (and instantaneous) interdealer market to sell or buy bonds in order to keep a zero inventory position. When a contact between a $L$-type seller and a dealer occurs, the dealer can instantaneously sell the bond at the inter-dealer clearing price $M$ to another dealer who is in contact with an $H$-type investor via the interdealer market. If

\footnotetext{
${ }^{8}$ Models analyze these issues include, for example, Berk and Green (2004), He and Xiong (2012a), Cheng and Milbradt (2012), and Suarez, Schroth, and Taylor (2014).

${ }^{9}$ This is an innocuous assumption made for exposition. Switching back from $L$ to $H$ is easily incorporated into the model. See the Appendix for details
} 
he does so, the bond travels from an $L$-type investor to an $H$-type investor with the help of the two dealers who are connected in the inter-dealer market.

For any aggregate state $s$, denote by $D_{l}^{s}$ the bond value for an investor with type $l \in\{H, L\}$. Denote by $B^{s}$ the bid price at which the $L$-type is selling his bond, by $A^{s}$ the ask price at which the $H$-type is purchasing this bond, and by $M^{s}$ the inter-dealer market price.

Following He and Milbradt (2014), we assume that the flow of $H$-type buyers contacting dealers is greater than the flow of $L$-type sellers contacting dealers; in other words, the secondary market is a seller's market. Then, Bertrand competition, the holding restriction, and excess demand from buyer-dealer pairs in the interdealer market drive the surplus of buyer-dealer pairs to zero. ${ }^{10}$

Proposition 1. Fix valuations $D_{H}^{s}$ and $D_{L}^{s}$. In equilibrium, the ask price $A^{s}$ and inter-dealer market price $M^{s}$ are equal to $D_{H}^{s}$, and the bid price is given by $B^{s}=\beta D_{H}^{s}+(1-\beta) D_{L}^{s}$. The dollar bid ask spread is $A^{s}-B^{s}=(1-\beta)\left(D_{H}^{s}-D_{L}^{s}\right)$.

As is typical in any model with decentralized trading, there is no single "market price" in our over-the-counter market. However, we use "market price" when we model the endogenous holding cost in equation (5). For simplicity, which is also consistent with market practice, we take the mid-price between the bid and the ask prices to be the "market price", i.e.,

$$
P^{s}=\frac{A^{s}+B^{s}}{2}=\frac{(1+\beta) D_{H}^{s}+(1-\beta) D_{L}^{s}}{2}
$$

Critically, the holding cost $h c_{s}$ in (5) is linear in individual bond valuations, which allows us to derive bond values in closed-form later.

Finally, empirical studies focus on the proportional bid-ask spread which is defined as the

\footnotetext{
${ }^{10}$ Introducing a situation in which there is less buyers than potential sellers, i.e., a buyer's market, would entail tracking the value functions of investors on the sideline and significantly complicate the pricing of the deterministic maturity bonds we use for the calibration below. As it, however, would not add additional economic insights pertaining to credit risk in particular, we do not consider this case here.
} 
dollar bid-ask spread divided by the mid price. In our model, it is

$$
\Delta^{s}(y, \tau)=\frac{2(1-\beta)\left(D_{H}^{s}-D_{L}^{s}\right)}{(1+\beta) D_{H}^{s}+(1-\beta) D_{L}^{s}}
$$

\subsection{Bankruptcy and Effective Recovery Rates}

When the firm's cash flow deteriorates, equity holders are willing to repay the maturing debt holders only when the equity value is still positive, i.e. the option value of keeping the firm alive justifies absorbing rollover losses and coupon payments. The firm defaults when its equity value drops to zero at some endogenous default threshold $y_{\text {def }}^{s}$, which is optimally chosen by equity holders. The bankruptcy costs is a fraction $1-\alpha$ of the value of the unleveled firm $v_{U}^{s} y_{\text {def }}^{s}$ value, where $v_{U}^{s}$ is given in (4).

There is strong empirical evidence that bankruptcy recovery rates $\alpha$ change with the aggregate state $s$ (see Chen (2010)). Moreover, as emphasized in He and Milbradt (2014), if bankruptcy leads investors to receive the bankruptcy proceeds immediately, then bankruptcy confers a "liquidity" benefit similar to a maturing bond. This "expedited payment" benefit runs counter to the fact that in practice bankruptcy leads to the freezing of assets within the company and a delay in the payout of any cash depending on court proceeding. ${ }^{11}$ Moreover, investors of defaulted bonds may face a much more illiquid secondary market (e.g., Jankowitsch, Nagler, and Subrahmanyam (2013)), and potentially a much higher holding cost once liquidity shocks hit due to regulatory or charter restrictions which prohibit institutions from holding defaulted bonds. These practical features, as shown in He and Milbradt (2014), lead to a type- and state-dependent bond recovery at the time of default:

$$
\mathbf{D}^{\text {def }}(y)=\left[\alpha_{H}^{G} v_{U}^{G}(y), \alpha_{L}^{G} v_{U}^{G}(y), \alpha_{H}^{B} v_{U}^{B}(y), \alpha_{L}^{G} v_{U}^{B}(y)\right]^{T}
$$

\footnotetext{
${ }^{11}$ For evidence on inefficient delay of bankruptcy resolution, see Gilson, John, and Lang (1990) and Ivashina, Smith, and Iverson (2013). In addition, the Lehman Brothers bankruptcy in September 2008 is a good case in point. After much legal uncertainty, payouts to the debt holders only started trickling out after about three and a half years.
} 
Here, $\boldsymbol{\alpha} \equiv\left[\alpha_{H}^{G}, \alpha_{L}^{G}, \alpha_{H}^{B}, \alpha_{L}^{B}\right]^{\top}$ are the effective bankruptcy recovery rates at default. As explained in Section 4.1.3, when calibrating $\boldsymbol{\alpha}$, we rely exclusively on the market price of defaulted bonds observed immediately after default, and the associated empirical bid-ask spreads, to pin down $\boldsymbol{\alpha}$.

\subsection{Summary of Setup}

Figure 1 summarizes the cash flows to debt and equity holders.

Panel A visualizes the cash flows to a debt holder in aggregate state $s$ (excluding jumps of the aggregate state). The horizontal lines depict the current log cash flow $y$. The top half of the graph depicts an $H$-type debt holder who has not been hit by a liquidity shock yet. This bond holder receives a flow of coupon $c$ each instant (all cash-flows in this figure are indicated by grey boxes). With intensity $m$, the bond matures and the investor receives the face value $p$. With intensity $\xi_{s}$ the investor is hit by a liquidity shock and transitions to an $L$-type investor who receives cash flows net of holding costs of $\left(c-h c_{s}(P)\right) d t$ each instant, where $P=\left[(1+\beta) D_{H}^{s}+(1-\beta) D_{L}^{s}\right] / 2$ is the endogenous secondary market mid price. With intensity $\lambda_{s}$ the $L$-type investor meets a dealer, sells the bond for $\beta D_{H}^{s}(y)+(1-\beta) D_{L}^{s}(y)$, and exits the market forever. To the debt holder, this is equivalent in value to losing the ability to trade but gaining a recovery intensity $\lambda_{s} \beta$ of transitioning back to being an $H$-type investor. Finally, when $y \leq y_{d e f}^{s}$, the firm defaults immediately and the bond holders recover $\alpha_{l}^{s} v_{U}^{s}(y)$ depending on their type $l \in\{H, L\}$.

Panel B visualizes the cash flows to equity holders. The horizontal lines depict the current $\log$ cash flow $y$, where the top (bottom) line represents the aggregate $G(B)$ state. Each instant, the equity holder receives a cash-flow $Y=e^{y}$ from the firm and pays the coupon $c$ to debt holders. As debt is of finite average maturity, there are cash flows caused by continuously rolling over the debt: by the law of large numbers, a flow $m$ of bonds come due each instant and each bond requires a principal payment of $p$. At the same time, the firm reissues these maturing bonds with their original specification and raises an amount (after issuance costs) 


\section{Figure 1: Schematic graphic of cash flows to debt and equity holders}

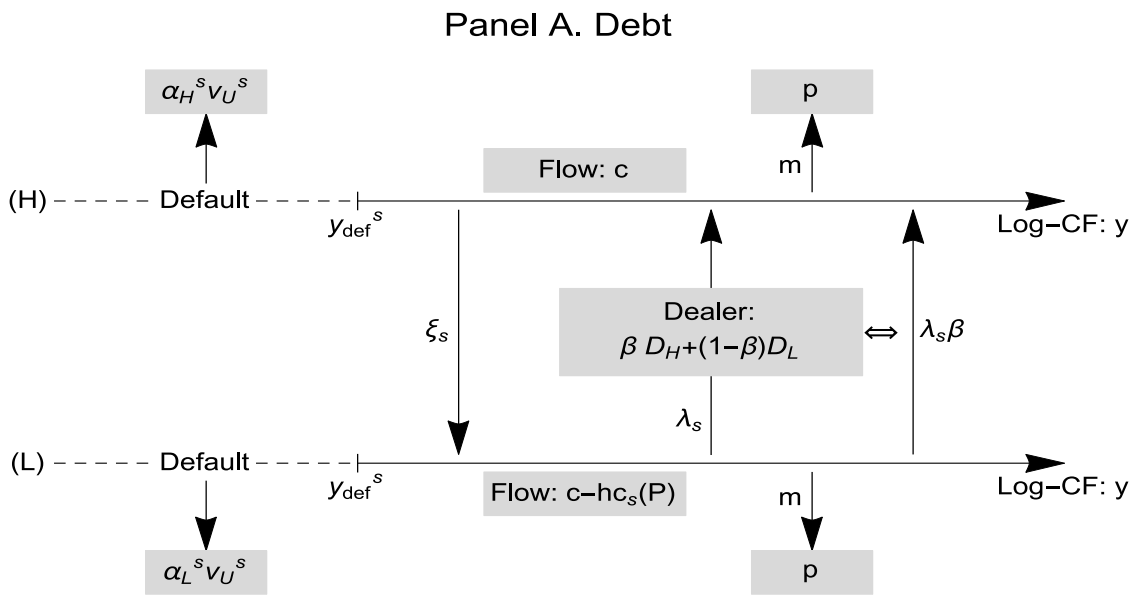

Panel B. Equity

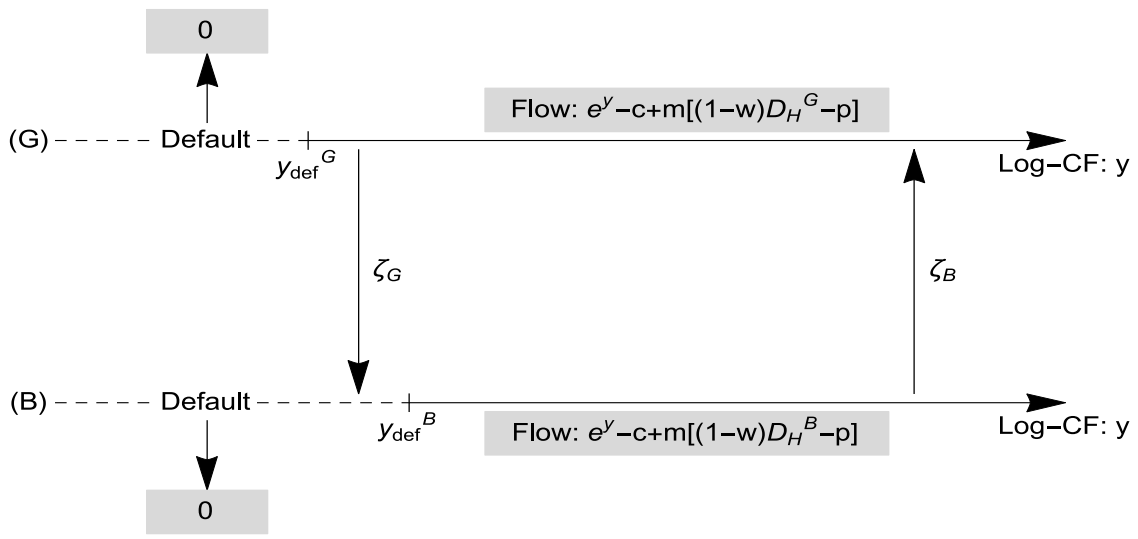

of $(1-\omega) D_{H}^{s}$ per bond depending on aggregate state $s \in\{G, B\}$. With intensity $\zeta_{G}$ the state switches from $G$ to $B$ and primary bond market prices decrease from $D_{H}^{G}(y)$ to $D_{H}^{B}(y)$ reflecting the higher default probability as well as the worsened liquidity in the market. In cases where $y \in\left(y_{d e f}^{G}, y_{d e f}^{B}\right)$ (as shown), the cash flows to equity holders are so low that they declare default immediately following the jump, receiving a payoff of 0 . Thus, the model features jumps to default even though the cash-flow process $y$ is continuous. Finally, with intensity $\zeta_{B}$, the state jumps from $B$ to $G$. Implicit in the model is that equity holders are raising new equity frictionlessly to cover negative cash flows before default.

Panel A and Panel B are connected via the primary market prices of newly issued bonds, 
i.e. $D_{H}^{s}(y)$ for $s \in\{G, B\}$. Although in the primary market the firm is able to locate and place newly issued bonds to $H$-type investors, the primary market prices reflect the secondary market illiquidity in Panel A, simply because forward-looking $H$-type investors take into account that they are facing the illiquid secondary market in the future once hit by liquidity shocks. Through this channel, the secondary market illiquidity enters the firm's rollover cash flows in Panel B and affects the firm's default decision.

\section{Model Solutions}

For $l \in\{H, L\}$ and $s \in\{G, B\}$, denote by $D_{l}^{(s)}$ the $l$-type bond value in aggregate state $s$, $E^{(s)}$ the equity value in aggregate state $s$, and $\boldsymbol{y}_{\text {def }}=\left[y_{d e f}^{G}, y_{d e f}^{B}\right]^{\top}$ the vector of endogenous default boundaries. We derive the closed-form solution for debt and equity valuations as a function of $y$ for given $\boldsymbol{y}_{\text {def }}$, along with the characterization of the endogenous default boundaries $\boldsymbol{y}_{\text {def }}$.

\subsection{Debt Valuations}

Because equity holders will default earlier in state $B$, i.e., $y_{\text {def }}^{G}<y_{\text {def }}^{B}$, the domains on which the bonds are "alive" change when the aggregate state switches. We deal with this issue by the method described below; see the Internet Appendix for the generalization of this analysis.

Define two intervals $I_{1}=\left[y_{\text {def }}^{G}, y_{\text {def }}^{B}\right]$ and $I_{2}=\left[y_{\text {def }}^{B}, \infty\right)$, and denote by $D_{l}^{s, i}$ the restriction of $D_{l}^{s}$ to the interval $I_{i}$, i.e., $D_{l}^{s, i}(y)=D_{l}^{s}(y)$ for $y \in I_{i}$. Clearly, $D_{l}^{B, 1}(y)=\alpha_{l}^{B} v_{U}^{B}(y)$ is in the "dead" state, so that the firm immediately defaults on interval $I_{1}$ when switching into state $B$ (from state $G$ ). In light of this observation, on interval $I_{2}=\left[y_{d e f}^{B}, \infty\right.$ ) all bond valuations denoted by $\mathbf{D}^{(2)}=\left[D_{H}^{G, 2}, D_{L}^{G, 2}, D_{H}^{B, 2}, D_{L}^{B, 2}\right]^{\top}$ are "alive."

Holding costs given liquidity shocks can be interpreted as negative dividends, which effectively lower the coupon flows that bond investors are receiving. Moreover, we directly apply the pricing kernel given in (1) without risk adjustments on the liquidity shocks. This 
treatment is justified by the assumption that the illiquid bond holding makes up only an infinitesimal part of the representative investor's portfolio. For further discussions, see footnote 7 and the end of Section 2.1.2.

Take $\mathbf{D}^{(2)}$ on interval $I_{2}$ as example. The bond valuation equation can be written in matrix form as follows:

$$
\begin{aligned}
\underbrace{\hat{\mathbf{R}} \cdot \mathbf{D}^{(2)}(y)}_{\text {Discounting, } 4 \times 1}= & \underbrace{\boldsymbol{\mu}}_{4 \times 4} \underbrace{\left(\mathbf{D}^{(2)}\right)^{\prime}(y)}_{4 \times 1}+\frac{1}{2} \underbrace{\boldsymbol{\Sigma}}_{4 \times 4} \underbrace{\left(\mathbf{D}^{(2)}\right)^{\prime \prime}(y)}_{4 \times 1}+\underbrace{\hat{\mathbf{Q}} \cdot \mathbf{D}^{(2)}(y)}_{\text {Transition }, 4 \times 1} \\
& +\underbrace{c \mathbf{1}_{4}}_{\text {Coupon }, 4 \times 1}+\underbrace{m\left[p \mathbf{1}_{4}-\mathbf{D}^{(2)}(y)\right]}_{\text {Maturity }, 4 \times 1}-\underbrace{\left[\boldsymbol{\chi} \cdot \mathbf{N}-\boldsymbol{\chi} \cdot \mathbf{W} \cdot \mathbf{D}^{(2)}(y)\right]}_{\text {Holding Cost }, 4 \times 1},
\end{aligned}
$$

where $\hat{\mathbf{R}}, \boldsymbol{\mu}, \boldsymbol{\Sigma}, \hat{\mathbf{Q}}, \boldsymbol{\chi}$, and $\mathbf{W}$ are given in the Internet Appendix. Here, the left-hand-side is the required return for holding the bond. On the right-hand-side, the first three terms capture the evolution of cash-flows and the aggregate state. The fourth term is the coupon payment, the fifth captures the effect of debt maturing, and the last gives the holding costs. Importantly for solvability, from (5), we see that endogenous debt valuations enter the holding cost linearly.

Proposition 2. The bond values on interval $i$ are given by

$$
\underbrace{\mathbf{D}^{(i)}}_{2 i \times 1}=\underbrace{\mathbf{G}^{(i)}}_{2 i \times 4 i} \cdot \underbrace{\exp \left(\boldsymbol{\Gamma}^{(i)} y\right)}_{4 i \times 4 i} \cdot \underbrace{\mathbf{b}^{(i)}}_{4 i \times 1}+\underbrace{\mathbf{k}_{0}^{(i)}}_{2 i \times 1}+\underbrace{\mathbf{k}_{1}^{(i)}}_{2 i \times 1} \exp (y),
$$

where the matrices $\mathbf{G}^{(i)}, \boldsymbol{\Gamma}^{(i)}$ and the vectors $\mathbf{k}_{0}^{(i)}, \mathbf{k}_{1}^{(i)}$ and $\mathbf{b}^{(i)}$ are given in the Internet Appendix.

\subsection{Equity Valuations and Default Boundaries}

When the firm refinances its maturing bonds, we assume that the firm can place newly issued bonds with $H$ investors in a competitive primary market subject to issuance costs. This implies that there are rollover gains/losses of $m\left[\mathbf{S}^{(i)} \cdot \mathbf{D}^{(i)}(y)-p \mathbf{1}_{i}\right] d t$ as a mass $m \cdot d t$ of 
debt holders matures at each instant. Here, $\mathbf{S}^{(i)}$ is a $i \times 2 i$ matrix that incorporates $\omega \in(0,1)$ as the proportional issuance cost in the primary corporate bond market, and selects the appropriate $D_{H} \cdot{ }^{12}$ Denote by double letters (e.g. $\mathbf{x x}$ ) a constant for equity that takes an analogous place to the single letter (i.e. $\mathbf{x}$ ) constant for debt. We can write down the valuation equation for equity on interval $I_{i}$. For instance, on interval $I_{2}$ we have

$$
\begin{aligned}
\underbrace{\mathbf{R R} \cdot \mathbf{E}^{(2)}(y)}_{\text {Discounting }, 2 \times 1}= & \underbrace{\boldsymbol{\mu} \boldsymbol{\mu}}_{2 \times 2} \underbrace{\left(\mathbf{E}^{(2)}\right)^{\prime}(y)}_{2 \times 1}+\frac{1}{2} \underbrace{\boldsymbol{\Sigma} \boldsymbol{\Sigma}}_{2 \times 2} \underbrace{\left(\mathbf{E}^{(2)}\right)^{\prime \prime}(y)}_{2 \times 1}+\underbrace{\mathbf{Q Q} \cdot \mathbf{E}^{(2)}(y)}_{\text {Transition }, 2 \times 1} \\
& +\underbrace{\mathbf{1}_{2} \exp (y)}_{\text {Cashflow }, 2 \times 1}-\underbrace{(1-\pi) c \mathbf{1}_{2}}_{\text {Coupon }, 2 \times 1}+\underbrace{m\left[\mathbf{S}^{(2)} \cdot \mathbf{D}^{(2)}(y)-p \mathbf{1}_{2}\right]}_{\text {Rollover }, 2 \times 1}
\end{aligned}
$$

where $\pi$ is the marginal tax rate, and matrices $\boldsymbol{\mu} \boldsymbol{\mu}, \boldsymbol{\Sigma} \boldsymbol{\Sigma}, \mathrm{QQ}$, and $\mathbf{R R}$ are given in the Internet Appendix.

Proposition 3. The equity value is given by

$$
\underbrace{\mathbf{E}^{(i)}(y)}_{i \times 1}=\underbrace{\mathbf{G G}^{(i)}}_{i \times 2 i} \cdot \underbrace{\exp \left(\boldsymbol{\Gamma} \boldsymbol{\Gamma}^{(i)} y\right)}_{2 i \times 2 i} \cdot \underbrace{\mathbf{b} \mathbf{b}^{(i)}}_{2 i \times 1}+\underbrace{\mathbf{K} \mathbf{K}^{(i)}}_{i \times 4 i} \underbrace{\exp \left(\boldsymbol{\Gamma}^{(i)} y\right)}_{4 i \times 4 i} \underbrace{\mathbf{b}^{(i)}}_{4 i \times i}+\underbrace{\mathbf{k} \mathbf{k}_{0}^{(i)}}_{i \times 1}+\underbrace{\mathbf{k} \mathbf{k}_{1}^{(i)}}_{i \times 1} \exp (y) \text { for } y \in I_{i}
$$

where the matrices $\mathbf{G} \mathbf{G}^{(i)}, \mathbf{\Gamma} \boldsymbol{\Gamma}^{(i)}, \mathbf{K} \mathbf{K}^{(i)}, \boldsymbol{\Gamma}^{(i)}$ and the vectors $\mathbf{k k}_{0}^{(i)}, \mathbf{k k}_{1}^{(i)}$ and $\mathbf{b}^{(i)}$ are given in the Internet Appendix.

Finally, the endogenous bankruptcy boundaries $\boldsymbol{y}_{d e f}=\left[y_{d e f}^{G}, y_{d e f}^{B}\right]^{\top}$ are given by the standard smooth-pasting condition:

$$
\left(\mathbf{E}^{(1)}\right)^{\prime}\left(y_{d e f}^{G}\right)_{[1]}=0, \text { and }\left(\mathbf{E}^{(2)}\right)^{\prime}\left(y_{\text {def }}^{B}\right)_{[2]}=0 \text {. }
$$

\footnotetext{
${ }^{12}$ Recall we assume that the firm issues to $H$-type investors in the primary market, which is consistent with our seller's market assumption in Section 2.2, i.e., there are sufficient $H$-type buyers waiting on the sidelines. For instance, for $y \in I_{2}=\left[y_{\text {def }}(B), \infty\right)$, we have $\mathbf{D}^{(2)}=\left[D_{H}^{G, 2}, D_{L}^{G, 2}, D_{H}^{B, 2}, D_{L}^{B, 2}\right]^{\top}$ and $\mathbf{S}^{(2)}=(1-\omega)\left[\begin{array}{llll}1 & 0 & 0 & 0 \\ 0 & 0 & 1 & 0\end{array}\right]$.
} 


\subsection{Model Implied Credit Default Swap}

One of the key empirical moments for bond liquidity used in this paper is the Bond-CDS spread, defined as Bond credit spread minus the spread of the corresponding Credit Default Swap (CDS). Since the CDS market is much more liquid than that of corporate bonds, following Longstaff, Mithal, and Neis (2005) we compute the model implied CDS spread under the assumption that the CDS market is perfectly liquid. ${ }^{13}$

Let $\tau$ (in years from today) be the time of default. Formally, if today is time $u$, then $\tau \equiv \inf \left\{t: y_{u+t} \leq y_{\text {def }}^{s_{u+t}}\right\}$ can be either the first time at which the log cash-flow rate $y$ reaches the default boundary $y_{d e f}^{s}$ in state $s$, or when $y_{d e f}^{G}<y_{t}<y_{\text {def }}^{B}$ so that a change of state from $G$ to $B$ triggers default. Thus, for a $T$-year CDS contract, the required flow payment $f$ is the solution to the following equation:

$$
\mathbb{E}^{\mathcal{Q}}\left[\int_{0}^{\min [\tau, T]} \exp (-r t) f d t\right]=\mathbb{E}^{\mathcal{Q}}\left[\exp \left(-r \tau 1_{\{\tau \leq T\}}\right) L G D_{\tau}\right],
$$

where $L G D_{\tau}$ is the loss-given-default, which is the bond face value $p$ minus its recovery value, where the recovery value is defined as the mid transaction price at default. If there is no default, no loss-given-default is paid out by the CDS seller. We calculate the flow payment $f$ that solves (14) using a simulation method. The CDS spread, $f / p$, is defined as the ratio between the flow payment $f$ and the bond's face value $p$.

\footnotetext{
${ }^{13}$ Arguably, the presence of the CDS market will in general affect the liquidity of the corporate bond market; but we do not consider this effect. A recent theoretical investigation by Oehmke and Zawadowski (2013) shows ambiguous results in this regard. Further, there is some ambiguity in the data about which way the illiquidity in the CDS market affects the CDS spread. Bongaerts, De Jong, and Driessen (2011) show that the sellers of CDS contracts earn a liquidity premium.
} 


\section{Calibration}

\subsection{Benchmark Parameters}

We calibrate the parameters governing firm fundamentals and pricing kernels to key moments of the aggregate economy and asset prices. Parameters governing time-varying liquidity conditions are calibrated to their empirical counterparts on bond turnover and observed bid-ask spreads.

\section{[TABLE 1 ABOUT HERE]}

\subsubsection{SDF and cash flow parameters}

In Table 1 we follow Chen, Xu, and Yang (2012) in calibrating firm fundamentals and investors' pricing kernel. Start from the investors' pricing kernel. To abstract from any term structure effects, we set risk the free rate $r_{G}=r_{B}=5 \%$ in both aggregate states; the choice of $5 \%$ is based on the time-series average of nominal 5- and 10-year interest rate from 1994 onwards. For simplicity, in this paper we do not model the liquidity premium for Treasuries and compute the credit spreads relative to the risk-free rate instead of the Treasury yields. ${ }^{14}$ Transition intensities give the duration of the business cycle (10 years for expansions and 2 years for recessions). The jump risk premium $\exp (\kappa)=2$ in state $G$ (and the state $B$ jump risk premium is the reciprocal of that of state $G$ ) is consistent with a long-run risk model with Markov-switching conditional moments and calibrated to match the equity premium (Chen (2010)). The price of risk $\eta$ is the product of relative risk aversion $\gamma$ and consumption volatility $\sigma_{c}: \eta=0.165(0.255)$ in state $G$ (state $B$ ) requires $\gamma=10$ and $\sigma_{c}=1.65 \%\left(\sigma_{c}=2.55 \%\right)$.

\footnotetext{
${ }^{14}$ It has been widely recognized (e.g., Duffie (1996), Krishnamurthy (2002), Longstaff (2004)) that Treasury yields are lower than the risk-free rate due to their special role in financial markets. In unreported results, we introduce (exogenous) state-dependent liquidity premia $\Delta_{s}$ for Treasuries and calibrate them using the spreads between 3-month general collateral repo rates and Treasury yields. This introduction of the $\Delta_{s}$ simply leads to level shifts between the spreads using the risk-free rate as the benchmark and those using the Treasury yield as benchmark. However, it makes our structural liquidity-default decomposition cumbersome.
} 
On the firm side, the cash-flow growth is matched to the average (nominal) growth rate of aggregate corporate profits. State-dependent systematic volatilities $\sigma_{m}^{s}$ are chosen to match equity return volatilities. Based on the empirical median debt maturity (including bank loans and public bonds reported in Chen, $\mathrm{Xu}$, and Yang (2012)) we set $m=0.2$ implying an average debt maturity of 5 years. We set the debt issuance cost $\omega$ in the primary corporate bond market to be $1 \%$ as in Chen (2010).

The idiosyncratic volatility $\sigma_{f}$ is chosen to match the default probability of Baa firms. There is no state-dependence of $\sigma_{f}$ as we do not have data counterparts for state-dependent Baa default probabilities. Finally, as explained later, the firm's cash-flow is determined from empirical leverage observed in the data.

Chen, Collin-Dufresne, and Goldstein (2009) argue that generating a reasonable equity Sharpe ratio is an important criterion for a model that tries to simultaneously match the default rates and credit spreads, as otherwise one can simply raise credit spreads by imposing unrealistically high systematic volatility and prices of risk. Our calibration implies an equity Sharpe ratio of 0.11 in state $G$ and 0.20 in state $B$, which are close to the mean firm-level Sharpe ratio for the universe of CRSP firms (0.17) reported in Chen, Collin-Dufresne, and Goldstein (2009).

\subsubsection{Secondary bond market illiquidity}

The liquidity parameters describing the secondary corporate bond market are less standard in the literature. We first fix the state-dependent intermediary meeting intensity based on anecdotal evidence, so that it takes a bond holder on average a week $\left(\lambda_{G}=50\right)$ in the good state and 2.6 weeks $\left(\lambda_{B}=20\right)$ in the bad state to find an intermediary to divest of all bond holdings. We interpret the lower $\lambda$ in state $B$ as a weakening of the financial system and its ability to intermediate trades. We then set bond holders bargaining power $\beta=0.05$ independent of the aggregate state, based on empirical work that estimates search frictions in secondary corporate bond markets (Feldhütter (2012)). 
We choose the intensity of liquidity shocks, $\xi_{s}$, based on observed bond turnover in the secondary market. As we are aiming to explain the observed Bond-CDS spreads, we focus on the sample with CDS contracts traded (a total of 1,313 firms). Their value-weighted turnover from 2005 to 2012 is about 3.1 per year; over the business cycle, the normal time turnover is 3.3 per year while the recession time turnover is around 2 times per year. ${ }^{15}$

In our model, given our choice of relative high meeting intensities $\left(\lambda_{s}\right)$, the turnover rate is almost entirely determined by the liquidity shock intensity $\xi_{s} \cdot{ }^{16}$ Importantly, all turnover in the secondary corporate bond market is driven by liquidity trades in our setting. Of course, in practice investors trade corporate bonds for reasons other than liquidity. Because during recession institutional investors are more likely to be hit by liquidity shocks and hence trade their bond holdings, we rely on the empirical turnover frequency during recessions to set $\xi_{B}=2$. To reduce the number of free parameters, we fix the the state- $G$ liquidity intensity $\xi_{G}=2$ as well.

The parameters $\chi_{s}$ 's in equation (5) are central to determining the endogenous holding costs and thus illiquidity of corporate bonds in secondary market. We calibrate $\chi_{G}=0.12$ and $\chi_{G}=0.17$ to target the bid-ask spread for investment grade bonds in both aggregate states. In light of the particular micro-foundation in Section 2.2.1 where $\chi_{s}$ is interpreted as the wedge between collateralized and uncollateralized borrowing costs, both numbers are higher than the typical observed TED (LIBOR-Tbill) spreads. However, TED spreads (using the uncollateralized borrowing rate among a select group of large and reputable banks) might underestimate the true cost of uncollateralized borrowing for a large set of firms. More importantly, as a quantitative paper, the state-dependent holding cost parameters $\chi_{s}$ in (5) are in reduced form and meant to capture factors beyond this particular micro-foundation of uncollateralized borrowing (see discussion in Section 2.2.1). Finally, we set $N=107$ (with par bond value of $p=100$ ) to roughly target the Bond-CDS spread for Baa rated bonds in

\footnotetext{
${ }^{15}$ In the TRACE whole sample from 2005 to 2012, the value-weighted turnover of corporate bonds during NBER recessions is about 0.7 times per year, and there are is no significant difference in bond turnover over the business cycle.

${ }^{16}$ The expected turnover is $\frac{\xi_{s} \lambda_{s}}{\xi_{s}+\lambda_{s}} \simeq \xi_{s}$ when $\lambda_{s} \gg \xi_{s}$.
} 
state $G .^{17}$

\subsubsection{Effective recovery rates}

As explained in Section 2.3, our model features type- and state-dependent recovery rates $\alpha_{l}^{s}$ for $l \in\{L, H\}$ and $s \in\{G, B\}$. We first borrow from the existing structural credit risk literature, specifically Chen (2010), who treats the traded prices right after default as recovery rates, and estimates recovery rates of $57.6 \% \cdot v_{U}^{G}$ in normal times and $30.6 \% \cdot v_{u}^{B}$ in recessions (recall $v_{U}^{s}$ is the unlevered firm value at state $s$ ).

Assuming that post-default prices are bid prices at which investors are selling, then Proposition 1 implies:

$$
0.5755=\alpha_{L}^{G}+\beta\left(\alpha_{H}^{G}-\alpha_{L}^{G}\right) \text {, and } 0.3060=\alpha_{L}^{B}+\beta\left(\alpha_{H}^{B}-\alpha_{L}^{B}\right) .
$$

We need two more pieces of information on bid-ask spreads of defaulted bonds to pin down the $\alpha_{l}^{s}$ 's. Edwards, Harris, and Piwowar (2007) report that in normal times (2003-2005), the transaction cost for defaulted bonds for median-sized trades is about 200bps. To gauge the bid-ask spread for defaulted bonds during recessions, we take the following approach. Using TRACE, we first follow Bao, Pan, and Wang (2011) to calculate the implied bid-ask spreads for low rated bonds ( $C$ and below) for both non-recession and recession periods. We find that relative to the non-recession period, during recessions the implied bid-ask spread is higher by a factor of 3.1. Given a bid-ask spread of 200bps for defaulted bonds, this multiplier implies that the bid-ask spread for defaulted bonds during recessions is about $620 \mathrm{bps}$. Hence we have

$$
2 \%=\frac{2(1-\beta)\left(\alpha_{H}^{G}-\alpha_{L}^{G}\right)}{\alpha_{L}^{G}+\beta\left(\alpha_{H}^{G}-\alpha_{L}^{G}\right)+\alpha_{H}^{G}} \text {, and } 6.2 \%=\frac{2(1-\beta)\left(\alpha_{H}^{B}-\alpha_{L}^{B}\right)}{\alpha_{L}^{B}+\beta\left(\alpha_{H}^{B}-\alpha_{L}^{B}\right)+\alpha_{H}^{B}} .
$$

\footnotetext{
${ }^{17}$ In the micro-foundation provided in Appendix A, given other baseline calibrations, the choice of $N=107$ and $\chi_{s}$ gives rise to model-implied haircuts that range from $10 \%$ to $25 \%$ depending on ratings. They are broadly consistent with BIS (2010) which gives a comprehensive survey conducted by the BIS Committee on the Global Financial System (including both Europe and US) for June 2007 and June 2009. The model implied haircuts are $9 \%$ for Aaa/Aa bonds, $10 \%$ for A, 12\% for Baa, and 18\% for Ba. In BIS (2010), the average haircuts for non-rated counterparties are $6.7 \%$ for Aaa/Aa rated bonds, $12 \%$ for Baa, and $23 \%$ for high yield bonds.
} 
Solving (15) and (16) gives us the estimates of: ${ }^{18}$

$$
\boldsymbol{\alpha}=\left[\alpha_{H}^{G}=0.5871, \alpha_{L}^{G}=0.5749, \alpha_{H}^{B}=0.3256, \alpha_{L}^{B}=0.3050\right] .
$$

These default recovery rates determine the bond recovery rate, a widely-used measure defined as the defaulted bond price divided by its promised face value. In our calibration, the implied bond recovery rate is $49.7 \%$ in state $G$ and $24.5 \%$ in state $B$. The unconditional average recovery rate is $44.6 \%$. These values are consistent with the average issuer-weighted bond recovery rate of $42 \%$ in Moody's recovery data over 1982-2012, and they capture the cyclical variations in recovery rates as documented in Chen (2010).

\subsection{Degree of freedom in calibration}

We summarize our calibration parameters in Table 1. Although there are a total of 29 parameters, most of them are "pre-fixed parameters " that are displayed in the upper part, Panel A, of Table 1. These are set either using the existing literature or based on moments other than the corporate bond pricing moments. We only freely pick (calibrate) four "calibrated parameters" displayed in the lower part, Panel B, of the table. These target the empirical moments that our model aims to explain: The idiosyncratic volatility $\sigma_{f}$ is picked to target Baa firm default probabilities; for holding cost parameters, $N$ is set to target the Baa state $G$ Bond-CDS spread; and $\chi_{G}$ and $\chi_{B}$ are picked to target investment grade bid-ask spreads in both states. As shown shortly, the number of degrees of freedom (4) is far below the number of our empirical moments that we aim to match.

We point out that in our model, the quantitative performance over the business cycle is less surprising given that our model takes (and sometimes, chooses) different exogenous parameters for the two aggregate states. Because our model links the secondary bond market liquidity to the firm's distance-to-default, our model's quantitative strength is more reflected

\footnotetext{
${ }^{18}$ This calculation assumes that bond transactions at default occur at the bid price. If we assume that transactions occur at the mid price, these estimates are $\alpha_{H}^{G}=0.5813, \alpha_{L}^{G}=0.5691, \alpha_{H}^{B}=0.3140, \alpha_{L}^{B}=0.2972$.
} 
in its cross-sectional performance. Further, as we choose the liquidity parameters (e.g. holding costs) to target turnover and bid-ask spreads, the matching of Bond-CDS spreads can be considered and additional measure of success of our model.

\subsection{Empirical Moments}

We consider four rating classes: Aaa/Aa, A, Baa, and Ba; the first three rating classes are investment grade, while $\mathrm{Ba}$ is speculative grade. We combine Aaa and Aa together because there are few observations for Aaa firms. We emphasize that previous calibration studies on corporate bonds focus on the difference between Baa and Aaa only, while we are aiming to explain the level of credit spreads across a wide range of rating classes. Furthermore, we report the model performance conditional on macroeconomic states, while typical existing literature only focus on unconditional model performance (Chen, Collin-Dufresne, and Goldstein (2009), Bhamra, Kuehn, and Strebulaev (2010), and Chen (2010)). We classify each quarter as either in "state $G$ " or "state $B$ " based on NBER recessions. As the " $B$ " state in our model only aims to capture normal recessions in business cycles, we exclude two quarters during the 2008 financial crisis, which are 2008Q4 and 2009Q1, to mitigate the effect caused by the unprecedented disruption in financial markets during crisis. ${ }^{19}$

\section{[TABLE 2 ABOUT HERE]}

\subsubsection{Default Probabilities}

The default probabilities for 5-year and 10-year bonds in the data column of Panel A in Table 2 are taken from Exhibit 33 of Moody's annual report on corporate default and recovery rates (2012), which provides cumulative default probabilities over the period of 1920-2011. Unfortunately, state-dependent measures of default probabilities over the business cycle are unavailable.

\footnotetext{
${ }^{19}$ For recent empirical research that focuses on the behavior of the corporate bond market during the 2007/08 crisis, see Dick-Nielsen, Feldhütter, and Lando (2012) and Friewald, Jankowitsch, and Subrahmanyam (2012).
} 


\subsubsection{Bond Spreads}

Our data of bond spreads is obtained using Mergent Fixed Income Securities Database (FISD) trading prices from January 1994 to December 2004, and TRACE data from January 2005 to June 2012. We follow the standard data cleaning process, e.g. excluding utility and financial firms. ${ }^{20}$ For each transaction, we calculate the bond credit spread by taking the difference between the bond yield and the treasury yield with corresponding maturity. Within each rating class, we average these observations in each month to form a monthly time series of credit spreads for that rating. We then calculate the time-series average for each rating conditional on the macroeconomic state (whether the month is classified as a NBER recession), and provide the conditional standard deviation for the conditional mean. To account for the autocorrelation of these monthly series, we calculate the standard deviation using Newey-West procedure with 15 lags.

We report the conditional means of bond spreads for each rating class and their corresponding conditional standard deviations for both 5-year and 10-year bonds in the data column in Panel B of Table 2. In the existing literature, Huang and Huang (2012) cover the period from the 1970's to the 1990's, and report an (unconditional) average credit spread of 55 bps for 4-year Aaa rated bonds, 65 bps for Aa, 96 for A, 158 for Baa, and 320 for Ba. Our unconditional 5-year average credit spreads which are the weighted average across conditional means reported in Panel B of Table 2 are fairly close to Huang and Huang (2012): 65 bps for Aaa/Aa, 100 bps for A, 167 for Baa, and 349 for Ba.

\subsubsection{Bond-CDS spreads}

Longstaff, Mithal, and Neis (2005) argue that because the market for CDS contracts is much more liquid than the secondary market for corporate bonds, the CDS spread should mainly reflect the default risk of a bond, while the credit spread also includes a liquidity premium to compensate for the illiquidity in the corporate bond market. Following Longstaff, Mithal, and

\footnotetext{
${ }^{20}$ For FISD data, we follow Collin-Dufresne, Goldstein, and Martin (2001). For TRACE data, we follow Dick-Nielsen (2009).
} 
Neis (2005), we take the difference between the bond credit spread and the corresponding CDS spread to get the Bond-CDS spread. This spread is our first empirical measure for the non-default risk of corporate bonds.

In more detail, we construct Bond-CDS spreads as follows. We first match FISD bond transaction data with CDS prices from Markit, and then difference the spreads, with two caveats. First, the data sample period only starts from 2005 when CDS data become available. Second, to address the potential selection issue, we follow $\mathrm{Chen}, \mathrm{Xu}$, and Yang (2012) and focus on firms that have both 5-year and 10-year bonds outstanding. The results are reported in the data column in Panel A in Table 2, which shows that Bond-CDS spreads are higher for lower rated bonds. ${ }^{21}$

Bond-CDS spread versus Bond-CDS basis One issue is worth further discussing. Our Bond-CDS spread is defined as the corporate bond yield minus the treasury yield with matching maturity, and then minus its corresponding CDS spread. Another closely related measure, the Bond-CDS basis, is of great interest to both practitioners and academic researchers. The only difference is on the risk-free benchmark: our Bond-CDS spread takes the Treasury yield as the benchmark, while Bond-CDS bases takes interest rate swap rate as the benchmark. For recent studies on Bond-CDS basis, see Gârleanu and Pedersen (2011) and Bai and Collin-Dufresne (2012).

The study of the Bond-CDS basis mostly focuses on limits-to-arbitrage during the turmoil of financial market, because the interest rate swap rate gives a more accurate measure of an arbitrager's financing cost. In contrast, our paper aims to explain total credit spreads, and we follow the corporate bond pricing literature in setting the Treasury yield as our benchmark. The credit spread includes both default and liquidity components. Treasuries are a better

\footnotetext{
${ }^{21} \mathrm{We}$ focus on investment grade bonds and Ba rated bonds (the high-end of speculative grade). Over this range, riskier bonds have higher Bond-CDS spreads. This monotonicity tends to be reversed toward the low-end of speculative grade bonds, which could be simply due to the fact that by definition bond yields are biased downward relative to CDS spreads (yields are calculated based on the stated maturity, which are substantially smaller than the actual duration for risky bonds due to imminent default.) Karakas, Hotchkiss, and Feldhutter (2014) offers another explanation outside of our model emphasizing the valuable control rights of bond holders in the event of corporate default.
} 
default-free benchmark, because the interest rate swap rate is the fixed leg of LIBOR, which is contaminated by default risk. Treasuries also serve as the illiquidity-free benchmark, where "liquidity" can be interpreted broadly to include market liquidity and funding liquidity that are captured by our model.

\subsubsection{Bid-Ask Spreads}

The second non-default measure that we study is bid-ask spreads in the secondary market for corporate bonds, whose model counterpart is given in (7). Previous empirical studies have uncovered rich patterns of bid-ask spreads across aggregate states and rating classes. More specifically, we combine Edwards, Harris, and Piwowar (2007) and Bao, Pan, and Wang (2011) to construct the data counterparts for the bid-ask spread, as Edwards, Harris, and Piwowar (2007) only report the average bid-ask spread across ratings in normal times (2003-2005). The ratings considered in Edwards, Harris, and Piwowar (2007) are superior grade (Aaa/Aa) with an bid-ask spread of 40 bps, investment grade (A/Baa) with an bid-ask spread of $50 \mathrm{bps}$, and junk grade (Ba and below) with a bid-ask spread of 70 bps. ${ }^{22}$ For each grade, we then compute the measure of liquidity in Roll (1984) as in Bao, Pan, and Wang (2011), which we use to back out the bid-ask spread ratio between $B$-state and $G$-state. We multiply this ratio by the bid-ask spread estimated by Edwards, Harris, and Piwowar (2007) in normal times (2003-2005) to arrive at a bid-ask spread measure for the $B$ state. These empirical estimates are reported in Panel B in Table 3.

\subsection{Model Performance on Default Risk and Credit Spreads}

\subsubsection{Calibration method}

For any given log cash-flow $y$, which links one-to-one to the firm's market leverage, we can compute the default probability and credit spread of bonds at 5 and 10 year maturity using

\footnotetext{
${ }^{22}$ We take the median size trade around 240K. Edwards, Harris, and Piwowar (2007) show that trade size is an important determinant for transaction costs of corporate bonds. But, for tractability reasons, we have abstracted away from trade size considerations.
} 
Monte-Carlo methods. ${ }^{23}$ As is typical in structural corporate bond pricing models, we find that the model implied default probability and total credit spread are highly nonlinear in market leverage (see Figure 2). ${ }^{24}$ The non-linearity inherent in the model implies, via Jensen's inequality, that the average credit spreads are higher than the spreads at average market leverage. This concern is empirically relevant, because the observed leverage distribution within each rating category is diverse as shown in Figure 3. We thus follow David (2008) in computing model implied aggregate moments. Specifically, we compute the market leverage (i.e., book debt over the sum of market equity and book debt) of each Compustat firm (excluding financial and utility firms and other standard filters) that has rating information between 1994 and 2012. We then match each firm-quarter observation in Compustat to its model counterpart based on the observed market leverage, compute the average across all firms, and repeat the procedure for each rating class, each maturity and each aggregate state (5 or 10 years). Hence, by construction, our model always exactly matches the data counterpart on the dimension of leverage.

Relative to the existing literature, our calibration aims to explain the level of credit spread across ratings, rather than differences between ratings. For instance, Chen, Collin-Dufresne, and Goldstein (2009), Bhamra, Kuehn, and Strebulaev (2010), and Chen (2010) focus on explaining the difference in spreads between Baa and Aaa rated bonds, which they consider the default component of Baa rated bonds under the assumption that the observed spreads for Aaa rated bonds are mostly driven by the liquidity premium. Because our framework endogenously models bond liquidity, we are able to match the total credit spreads that we observe in the data across the superior ratings (Aaa/Aa) down to the high end of speculative rated bonds (here $\mathrm{Ba})$.

Another important dimension that our paper improves upon over the existing literature

\footnotetext{
${ }^{23}$ Recall that for tractability we assume that bonds have random maturity. In our calibration, we study bonds with deterministic maturities, which can be viewed as some infinitesimal bonds in the firm's aggregate debt structure analyzed in Section 2.1.3. Since the debt valuation derived in Proposition 2 does not apply, we rely on Monte-Carlo methods.

${ }^{24}$ The reason that default rate is higher in state $G$ for the same market leverage is that the market leverage is higher in state $B$ for the same book leverage due to the drop in equity value.
} 
Figure 2: Model Implied Nonlinearity. This graph demonstrates that the implied default probability and credit spreads are nonlinear functions of the firm's market leverage. The model parameters are given in Table 1.
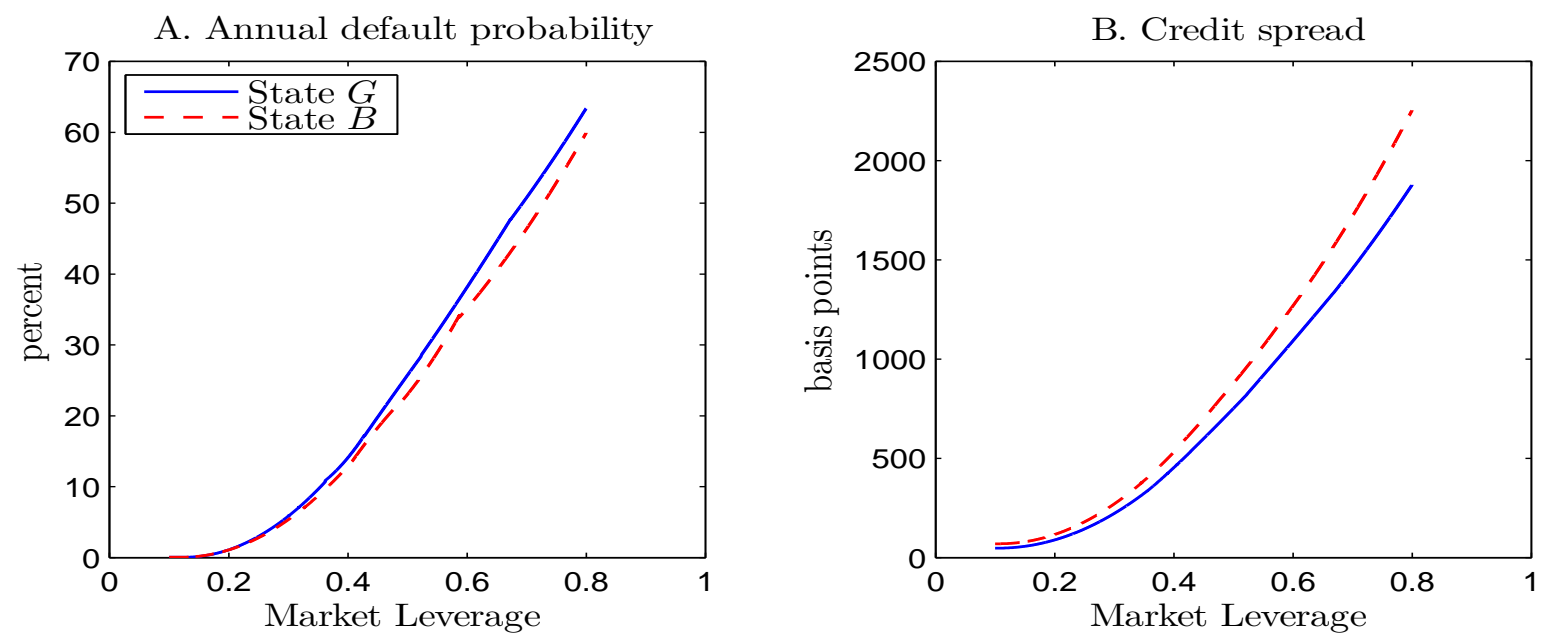

is on the matching of conditional means of credit spreads. Because the success of Chen, Collin-Dufresne, and Goldstein (2009), Bhamra, Kuehn, and Strebulaev (2010), and Chen (2010) hinges on the idea that the bond's payoff is lower in recessions with a higher marginal utility of consumption, checking whether the model implied bond spreads conditional on recessions match their empirical counterparts can be viewed as a disciplinary test for the mechanism proposed by those papers.

\subsubsection{Calibration results}

Table 2 presents our calibration results on default probabilities (Panel A) and credit spreads across four rating classes (Panel B), for both 5-year and 10-year bonds.

Our calibration exercise puts more emphasis on the 5 -year horizon. ${ }^{25}$ The reason that we focus more on the 5-year, rather than the 10-year, horizon is that this paper aims to explain the non-default component of corporate bonds. The Bond-CDS spreads require the input of observed CDS spreads. It is well known that CDS contracts are at their most liquid at 5-year

\footnotetext{
${ }^{25}$ More specifically, within the reasonable range used in the literature, we have chosen the state-dependent risk price $\eta$ and systematic volatility $\sigma_{m}$ to deliver an overall good match for 5-year Baa rated bonds.
} 
Figure 3: Empirical Distribution of Market Leverage for Compustat Firms by Aggregate State and Rating classes. We compute quasi-market leverage for each firm-quarter observation in the Compustat database from 1994-2012, excluding financials and utilities. State $B$ is classified as quarters for which at least two months are NBER recession month. The remaining quarters are $G$ state. We drop financial and utility firms in our sample, as well as firms with zero leverage. We exclude the crisis quarters 2008Q4 and 2009Q1.

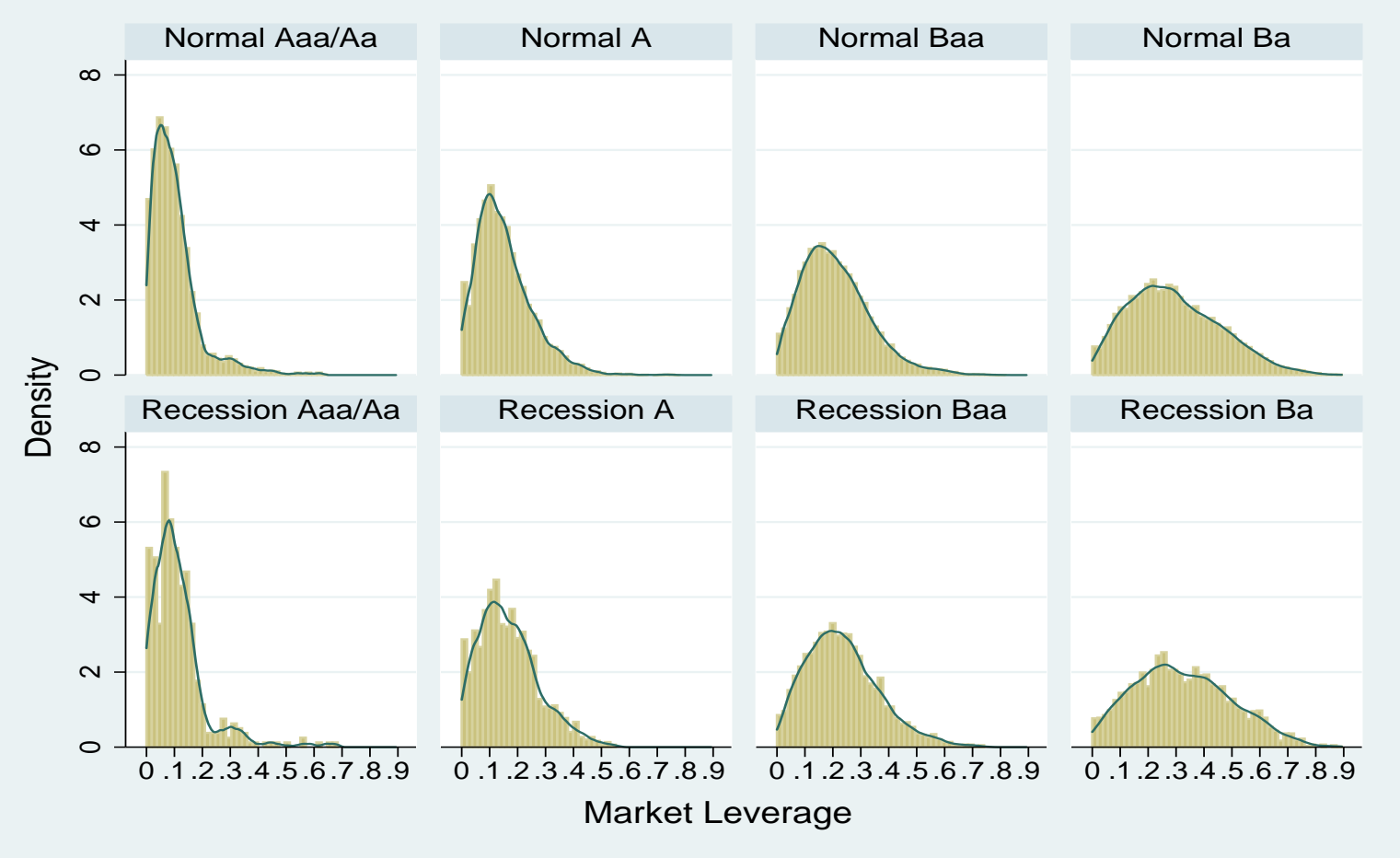

maturities (e.g., Longstaff, Mithal, and Neis (2005)). Since our model assumes a perfectly liquid CDS market, focusing on the 5-year horizon mitigates the potential liquidity effect of the CDS market in biasing our calibration results.

5-year default probabilities and credit spreads For 5-year bond maturities, our quantitative model is able to deliver a decent matching for both cross-sectional and state-dependent patterns in default probabilities and credit spreads.

For superior grade bonds (rated Aaa/Aa), our model gives a reasonable match for 5-year credit spreads: in state $G$, the model predicts 72.9 bps while the data counterpart is 55.7 bps; in state $B$, we have 99 bps in the model versus 107 bps in the data. Thanks to introducing 
liquidity into the structural corporate bond pricing model, we are able to produce reasonable credit spreads for Aaa/Aa bonds conditional on empirically observed default probabilities. The model implied default probability is $0.5 \%$, just below the data counterpart of $0.7 \%$.

For lower rated bonds, the match on default probability is quite satisfactory. For instance, for Ba rated bonds, the model implied default probability is $9.9 \%$, matching well with the 9.8\% value reported by Moody's. Overall, relative to the data the model implied credit spread tends to overshoot in state $G$ and undershoot in state $B$, but the match remains reasonable.

10-year default probabilities and credit spreads While our model is able to quantitatively match the cross-sectional and state-dependent pattern for the credit spreads of 5 -year bonds, the matching for 10-year bonds is less satisfactory. The general pattern is that although the default probabilities match their data counterparts reasonably well, the model implied conditional credit spreads for 10-year bonds overshoot the empirical moments at a significant margin, suggesting that the model implied term structure of credit spreads is steeper than the data suggests. ${ }^{26}$ Certain interesting extensions of our model (e.g., introducing jumps in cash flows that are more likely to occur in state $B$ ) should help in this dimension, and we leave it to future research to address this issue.

\subsection{Model Performance on Non-Default Risk}

Our model features an illiquid secondary market for corporate bonds, which implies that the equilibrium credit spread must compensate the bond investors for bearing not only default risk but also liquidity risk. This new element allows us to investigate the model's quantitative performance on dimensions specific to bond market liquidity, i.e., Bond-CDS spreads and bid-ask spreads, in addition to default probabilities and credit spreads on which the previous literature has focused.

\footnotetext{
${ }^{26}$ In unreported results, we find that the method of David (2008) which addresses the nonlinearity in the data (caused by the diverse distribution in leverage) has helped our model greatly to deliver a flatter term structure. This finding is consistent with Bhamra, Kuehn, and Strebulaev (2010). Nevertheless, this treatment is not strong enough to get the term structure right.
} 


\subsubsection{Bond-CDS Spread}

Recall that we assume a perfectly liquid CDS market in Section 3.3. In practice, although much more liquid than the secondary corporate bond market, the CDS market is still not perfectly liquid. As explained above, to mitigate this effect we have focused on bonds with 5-year maturity, because 5 -year CDS contracts are traded with the most liquidity. ${ }^{27}$

5-year Bond-CDS spread Similar to the procedure in Section 4.4, following David (2008) we obtain our model-implied aggregate moments by first calculating the Bond-CDS spread for each firm-quarter observation for the Bond-CDS firm sample (after 2005) based on its market leverage, conditional on the macroeconomic state.

\section{[TABLE 3 ABOUT HERE]}

The quantitative matching of Bond-CDS spreads, which is reported in Panel A in Table 3 , is reasonably good for 5-year bonds. Overall, on the state-dependent dimension, the matching on state $G$ is close, but the model undershoots the data counterpart in state $B$. Cross-sectionally, the model implied slope with respect to rating classes of the Bond-CDS spread is flatter than its data counterpart. For instance, in state $B$, the Bond-CDS spread goes from 76 bps for Aaa/Aa-rated bonds to 227 bps for Ba-rated bonds in the date, while the model explains about $55 \%$ of this variation (from 74.5 bps of Aaa/Aa to 160 bps of Ba).

Overall, our model delivers the right magnitude for the empirically observed Bond-CDS spreads. The matching across macroeconomic states is better than the matching across the four rating categories, in that our model seems to produce too little variation ranging from superior grade bonds (Aaa/Aa) to speculative grade bonds (Ba). One possible avenue to explore in future research which may help generate rating-dependent liquidity is that bonds with different ratings should have different clienteles.

\footnotetext{
${ }^{27}$ Because the CDS market is a zero-net-supply derivative market, how the secondary market liquidity of CDS market affects the pricing of CDS depends on market details. Bongaerts, De Jong, and Driessen (2011) show that the sellers of CDS contract earn a liquidity premium.
} 
10-year Bond-CDS spreads and term structure Let us next consider 10-year bonds. Similar to the discussion at the end of Section 4.4, one area in which our model clearly fails is to replicate a slightly downward sloping Bond-CDS term structure in the data. In our data from 2005 to 2012, the 5-year Bond-CDS spread is slightly higher than the 10-year counterpart across all rating categories, subject to the caveat that the difference may not be statistically significant taking standard deviations into account. It is worth noting that this downward sloping term structure in Bond-CDS spreads is inconsistent with the robust finding of longer-maturity bonds being less liquid documented in the empirical literature (e.g., Edwards, Harris, and Piwowar (2007); Bao, Pan, and Wang (2011)). In fact, Longstaff, Mithal, and Neis (2005) report a positive relation between Bond-CDS spread and maturity in their sample.

From a theoretical perspective, the model implied term structure for Bond-CDS spreads is upward sloping for investment grade bonds, but may turn flat or even downward sloping for firms that are close to default. ${ }^{28}$ However, the observed leverages in our Bond-CDS firm sample are relatively low, leading to upward-sloping Bond-CDS spreads for all ratings.

One possible explanation, which is outside our model, for the downward sloping Bond-CDS spreads in the maturity dimension is that CDS spreads at different maturities are affected by liquidity differently. It is well recognized that CDS contracts are most liquid at the 5-year horizon when measured by the number of dealers offering quotes. If dealers are mainly selling CDS protections to regular investors and they possess market power (consistent with the empirical evidence in Bongaerts, De Jong, and Driessen (2011)), then the premium of 10-year CDS contracts that are only offered by a small number of dealers tend to be higher than the price of 5-year CDS contracts with more competitive dealers. This may contribute to the relatively lower 10-year Bond-CDS spreads.

\footnotetext{
${ }^{28}$ The reason is similar to the inverted term structure of credit spreads for bonds with lower distance-todefault in standard default-driven models. For bonds that are close to default, the bond's stated maturity matters little, thus 5-year and 10-year bonds face similar illiquidity. Thus, the illiquidity discount per year (for its stated maturity) is higher for 5-year bonds, leading to downward sloping curve for Bond-CDS spreads for risky bonds.
} 


\subsubsection{Bid-Ask Spread}

Our second measure of the non-default component is bid-ask spreads, whose empirical counterparts are given in Panel B of Table 3. On the model side, again we rely on the empirical leverage distribution in Compustat of firms across ratings and aggregate states to calculate our model implied bid-ask spreads. Since the average maturity in TRACE data is around 8 years, the model implied bid-ask spread is calculated as the weighted average between the bid-ask spread of a 5-year bond and a 10-year bond.

Our model is able to generate both cross-sectional and state-dependent patterns that quantitatively match what we observe in the data, especially in normal time. As mentioned before, we calibrate two state-dependent holding cost parameters $\left(\chi_{G}\right.$ and $\left.\chi_{B}\right)$ to match the bid-ask spread of investment grade bonds over macroeconomic states. Thus, it is less surprising that we are able to match the state-dependent pattern that bid-ask spreads more than double when the economy switches from state $G$ to state $B$. Cross sectionally, in normal times the average bid-ask spread is 38 bps for superior grade bonds, 50 bps for investment grade bonds, and 91 bps for junk grade bonds, which are close to the data taken from Edwards, Harris, and Piwowar (2007). The quantitative matching during recessions is also satisfactory. Although not reported here, the model-implied bid-ask spread of longer-maturity bonds is higher than that of shorter-maturity bonds, which is consistent with previous empirical studies (eg. Edwards, Harris, and Piwowar (2007); Bao, Pan, and Wang (2011)).

\subsection{Quantitative performance relative to benchmark models}

\subsubsection{What if the secondary market is perfectly liquid?}

Compared to earlier credit risk models that also incorporate macroeconomic risks, such as Chen, Collin-Dufresne, and Goldstein (2009), Bhamra, Kuehn, and Strebulaev (2010), and Chen (2010), our model adds an illiquid secondary market for corporate bonds. By setting either the holding cost for type $L$ investors, or the liquidity shock intensity, to zero (i.e., either 
$\chi_{s}=0$ or $\xi_{s}=0$ ), we see what our model calibration implies about default risk and credit spreads in the absence of liquidity frictions, and thus helps isolate the effects of secondary market illiquidity.

With the same baseline parameters except $\chi_{s}=0$, we repeat the same procedure as before (i.e., locate the corresponding cashflow level $y$ that delivers the observed quasi market leverage for Compustat firms) to generate the implied moments on default probabilities, credit spreads, and Bond-CDS spreads. The results are reported in the rows " $\chi=0$ " in Table 2 and Table 3. With $\chi_{s}=0$, the credit spreads become significantly lower, and more so for higher rated bonds. For highly rated Aaa/Aa firms, in state $G$ the 5 -year spread falls from 72.9 bps to $10.1 \mathrm{bps}$ (compared to the average spread of $55.7 \mathrm{bps}$ in the data), while in state $B$ it falls from 99 bps to 12.9 bps (compared to 107 bps in the data). Credit spreads for low-rated firms also fall, but by less in relative terms.

Further, though not reported in Table 3, setting $\chi_{s}=0$ generates model implied bid-ask spreads that are identically zero and Bond-CDS spreads that are close to zero. ${ }^{29}$

Besides the credit spreads, shutting off the secondary market illiquidity lowers modelimplied default probabilities as well. Quantitatively, the reduction for highly rated 5-year bonds about 20\% 30\%, while it is about $17 \%$ for speculative grade bonds. This is because secondary market illiquidity raises the rollover risk for firms, which in turn raises the probability of default.

\subsubsection{What if the holding cost does not depend on distance-to-default?}

As emphasized, our paper differs from He and Milbradt (2014) in several dimensions. First, our model introduces time-varying Markov aggregate states. This work-horse setting in structural corporate bond pricing models proves to be successful in distinguishing risk-neutral measures from physical measures. As a result, our quantitative exercise matches the cross-

\footnotetext{
${ }^{29}$ Bond-CDS spreadsheet are not exactly zero due to the different methods in which we calculate bond yields and CDS spreads. For instance, for long-term (say 20 years) bonds that are close to default, credit spreads - which effectively assume that default risk is averaged out over 20 years - tend to be much lower than CDS spreads.
} 
sectional default probabilities and leverage distributions observed in the data, a task that He and Milbradt (2014) does not perform.

More importantly, in equation (5) we allow the holding costs for bond investors hit by liquidity shocks to be decreasing in the bonds with lower distance-to-default. This generalization is important in generating endogenous cross-sectional pattern in bond liquidity that are close to the data. To illustrate this point, we consider another benchmark following He and Milbradt (2014) but with Markov aggregate states. More precisely, the alternative model, labeled by " $h c_{s}$," is the model considered here but with state-dependent holding costs which no longer depend on the firm's distance-to-default; recall that our model has holding costs depend on bond price, i.e., $h c_{s}(P)$. The calibration takes the same baseline parameters, but chooses $h c_{s}$ so that the implied bid-ask spreads for investment grade bonds in state $s=G, B$ match their empirical counterparts, as shown in the row of " $h c_{s}$ " in Table 3 Panel B. We then repeat the same leverage-matching procedure as before and report the model implied moments in the row of " $h c_{s}$ " in Table 2 and Table 3. Not surprisingly, relative to our model, the " $h c_{s}$ " model fails to deliver a sizable cross-sectional differences in bond illiquidity across different ratings. ${ }^{30}$

\section{Structural Default-Liquidity Decomposition}

Our structural model of corporate bonds features an interaction between default and liquidity in determining the credit spreads of corporate bonds. This default-liquidity interaction is manifested in a lower default probability in the absence of liquidity frictions (the rows " $\chi=0$ " in Table 2). Put differently, one needs to take into account the interactions between default risk and liquidity risk for a precise default-liquidity decomposition of credit spreads.

\footnotetext{
${ }^{30}$ Qualitatively, the endogenous default-illiquidity relation does not rely on the assumption of holding costs being decreasing in the firm's distance-to-default. As emphasized by He and Milbradt (2014) with constant holding cost, an endogenous default-illiquidity loop arises as long as bond investors face a worse liquidity in the post-default secondary bond market. In the calibration considered in He and Milbradt (2014), there is a reasonable cross-sectional difference despite a constant holding cost. Our results shown in Table 2 and Table 3 indicate the importance of matching default probabilities and leverage distributions in quantitative exercises.
} 
It has been common practice in the empirical literature to decompose credit spreads into liquidity and default components in an additive way, such as in Longstaff, Mithal, and Neis (2005). From the perspective of our model, this "intuitively appealing" decomposition tends to over-simplify the role of liquidity in determining the credit spread. More importantly, the additive structure often leads to a somewhat misguided interpretation that liquidity or default is the cause of the corresponding component, and each component would be the resulting credit spread if we were to shut down the other channel.

Which decomposition one uses has important implications for considering policy related questions. For instance, as our proposed decomposition will highlight, part of the default risk comes from the illiquid secondary market. Thus, when policy makers are considering providing liquidity to the market, besides the direct effect on the credit spread by improving liquidity, they should account for the indirect effect in lowering the default risk via the rollover channel. The traditional perspective often overlooks this indirect effect, a quantitatively important effect according to our study as we show below.

\subsection{Decomposition Scheme}

We propose a structural decomposition that nests the additive default-liquidity decomposition common in the literature. Specifically, we further decompose the default part into a puredefault and a liquidity-driven-default parts, and similarly decompose the liquidity part into a pure-liquidity and a default-driven-liquidity parts:

$$
\hat{c s}=\overbrace{\hat{c} s_{\text {pure } D E F}+\hat{c s} s_{L I Q \rightarrow D E F}}^{\text {Default Component } \hat{c s}_{D E F}}+\overbrace{\hat{c s_{\text {pure } L I Q}+\hat{c s}_{D E F \rightarrow L I Q}}}^{\text {Liquidity Component } \hat{c}_{L I Q}}
$$

This way, we separate causes from consequences, and emphasize that lower liquidity (higher default) risk can lead to a rise in the credit spread via the default (liquidity) channel. Recognizing and further quantifying this endogenous interaction between liquidity and default is important in evaluating the economic consequence of policies that are either improving 
market liquidity (e.g., Term Auction Facilities or discount window loans) or alleviating default issues (e.g, direct bailouts). This decomposition has been proposed in He and Milbradt (2014), but we believe the quantitative implication is more trustworthy given the more advanced calibration methodology in our paper.

Let us start by considering the default component. Imagine a hypothetical investor who is not subject to liquidity frictions and consider the spread that this investor demands over the risk-free rate. The resulting spread, denoted by $\hat{c} \hat{s}_{D E F}$, only prices the default event given the unchanged default threshold $y_{\text {def }}^{s}$, in line with Longstaff, Mithal, and Neis (2005) who use information from the relatively liquid CDS market to back out the default premium. Importantly, the default boundaries $y_{d e f}^{s}$ 's in calculating $\hat{c} s_{D E F}$ are the ones that arise out of solving the model with liquidity frictions in equation (13). ${ }^{31}$

In contrast, we define the "Pure-Default" component $\hat{c} s_{\text {pureDEF }}$ as the spread implied by the benchmark Leland model without secondary market liquidity frictions at all (e.g., setting $\xi_{s}=0$ or $\left.\chi_{s}=0\right)$. Because the liquidity of the bond market leads to less rollover losses, equity holders default less often, i.e., $y_{\text {def }}^{\text {Leland,s }}<y_{\text {def }}^{s}$, where $y_{\text {def }}^{\text {Leland,s denotes the endogenous default }}$ boundaries in the absence of secondary market illiquidity. The distinction between default boundaries implies a smaller pure-default component $\hat{c} s_{\text {pure } D E F}$ than the default component $\hat{c} s_{D E F}$. The difference $\hat{c} s_{D E F}-\hat{c} s_{\text {pure } D E F}$ gives the "Liquidity-Driven Default" component, which quantifies the effect that the illiquidity of secondary bond markets makes default more likely.

Next, let us consider the liquidity side. The liquidity component, in line with Longstaff, Mithal, and Neis (2005), is defined as $\hat{c s}_{L I Q} \equiv \hat{c s}-\hat{c} \hat{S}_{D E F}$. That is to say, the liquidity component is the difference between the total credit spread $\widehat{c s}$ implied by our model, and that required by a hypothetical investor without liquidity frictions, i.e., the spread $\hat{c} s_{D E F}$. Following a similar treatment to the default component, we further decompose $\hat{c s}_{L I Q}$ into a "Pure-Liquidity" component and a "Default-driven Liquidity" component. Let $\hat{c} s_{\text {pure LIQ }}$

\footnotetext{
${ }^{31}$ Hypothetically, this is the situation where all other bond investors are still facing liquidity frictions as modeled. Hence, the equity holders' default decision is not affected.
} 
be the spread of a bond that is subject to liquidity frictions as in Duffie, Gârleanu, and Pedersen (2005) but does not feature any default risk; this is the spread implied by our model as $P^{s}=p$ in equation (5) so that the bond price never drops (hence default free). The residual $\hat{c s}_{L I Q}-\hat{c s_{\text {pure } L I Q}}$ is what we term the default-driven liquidity part of our credit spread. Economically, when distance-to-default falls, lower bond prices give rise to a higher holding cost, which contributes to the default-driven liquidity part.

\subsection{Default-Liquidity Decomposition}

\subsubsection{Level of credit spreads}

We perform the above default-liquidity decomposition for 5-year bonds. We follow the same procedure as in Section 4.4.1, i.e., first identify the cash-flow state at the firm-quarter level based on empirical leverage observed in Compustat, then aggregate them over firms and quarters.

The decomposition results for each aggregate state are presented in Panel A of Table 4, and graphically in Panel A and B of Figure 4. For each component, we report its absolute level in bps, as well as the percentage contribution to the credit spread. In unreported results, we find that the decomposition results are largely unchanged when we vary the calibrated values of $\chi_{s}$.

As expected, the "pure default" component not only increases during recessions, but also rises for lower rated bonds. The fraction of credit spreads that can be explained by the "pure default" component starts from only 13\% for Aaa/Aa rated bonds, and monotonically increases to about $50 \%$ for Ba rated bonds. Not surprisingly, the "pure liquidity" component is higher in state $B(61 \mathrm{bps})$ than state $G(46 \mathrm{bps})$, but mechanically does not vary across ratings as $\chi_{s}$ is fixed within state. This is because the "pure liquidity" component captures the liquidity premium for a security whose holding cost is independent of ratings but higher in state $B$.

The remainder of the observed credit spreads, which is around $25 \% \sim 40 \%$ depending on 
Figure 4: Structural Liquidity-Default Decomposition for 5-Year Bonds Across Ratings. Graphical illustrations based on the data reported in Table 4. For detailed explanations see Table 4.
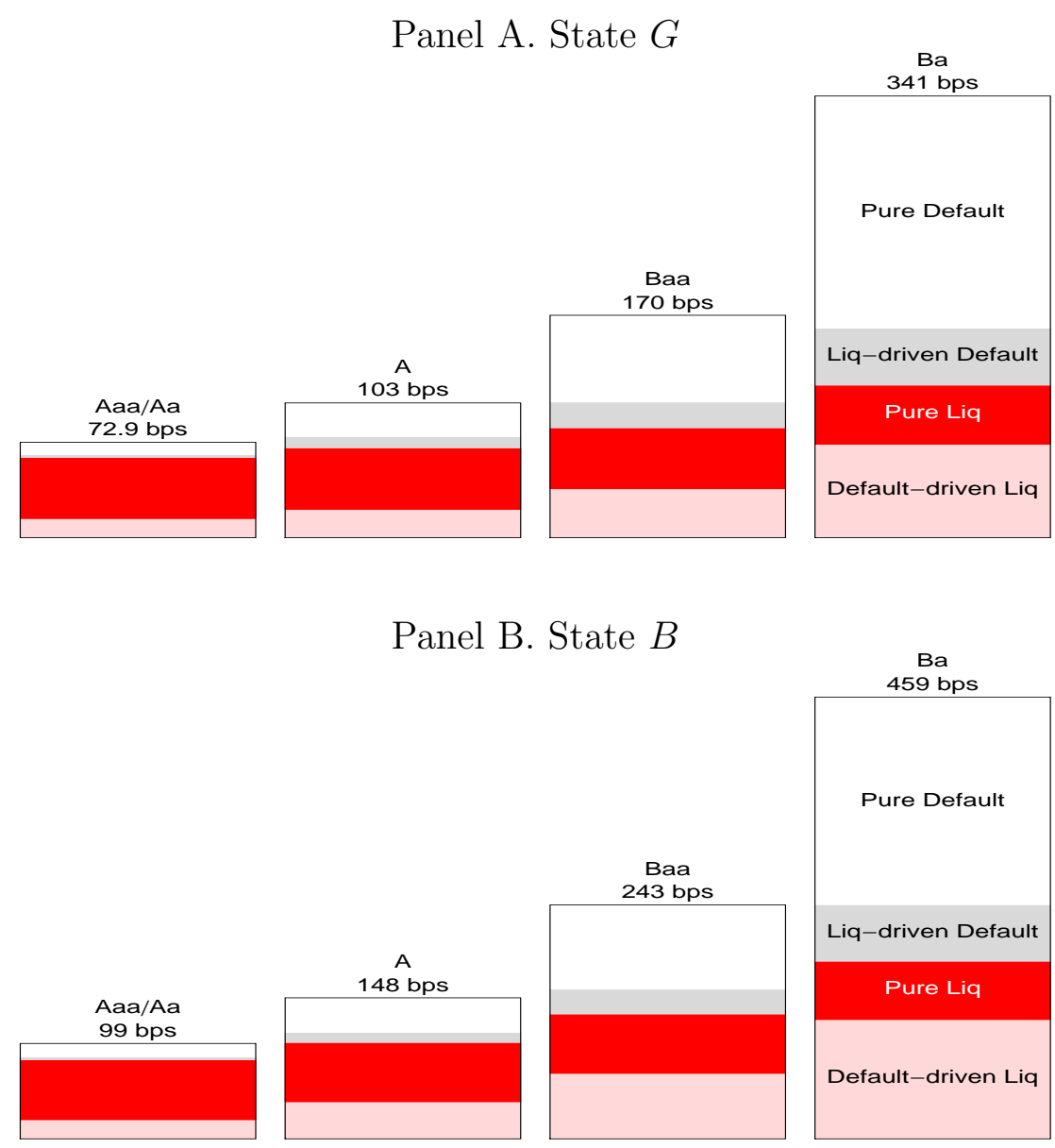

Panel C. Changes from state $G$ to $B$

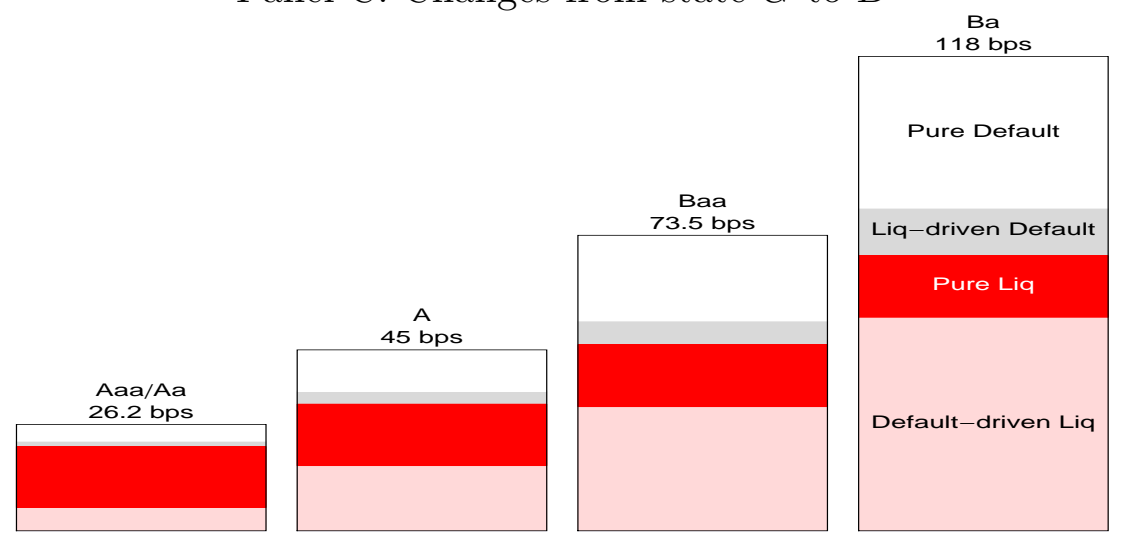


the rating, can be attributed to the novel interaction terms, either "liquidity-driven default" or "default-driven liquidity." The "liquidity-driven default" part captures how corporate endogenous default decisions are affected by secondary market liquidity frictions via the rollover channel, which is quantitatively small for the highest rating firms (about $4 \%$ for Aaa/Aa rated bonds). As expected, its quantitative importance rises for low rating bonds: for Ba rated bonds, the liquidity-driven default accounts for about $13 \%$ of observed credit spreads.

The second interaction term, i.e., the "default-driven liquidity" component, captures how secondary market liquidity endogenously worsens when a bond is closer to default. Given a more illiquid secondary market for defaulted bonds, a lower distance-to-default leads to a worse secondary market liquidity because of the increased holding cost in (5). Different from "liquidity-driven default," the "default-driven liquidity" component is significant across all ratings: it accounts for about $20 \sim 27 \%$ of the credit spread when we move from Aaa/Aa ratings to Ba ratings.

Comparison to Longstaff, Mithal, and Neis (2005) How do our decomposition results compare to those documented in Longstaff, Mithal, and Neis (2005)? Based on CDS spreads and a structural model, Longstaff, Mithal, and Neis (2005) estimate that for 5-year Aaa/Aa rated bonds, the default component is about $51 \%$ of their credit spreads. For lower ratings, they report $56 \%$ for A, $71 \%$ for Baa, and $83 \%$ for Ba.

Overall, our decomposition in Table 4 gives a much lower default component compared to Longstaff, Mithal, and Neis (2005). More specifically, by adding up the "pure-default" and "liquidity-driven default" components, we have a default component of about $17 \%$ for Aaa/Aa rated bonds, $33 \%$ for A, $50 \%$ for Baa, and $64 \%$ for Ba. This discrepancy is mostly due to the fact that we have a much lower empirical ratio between CDS spread and credit spreads, especially for investment grade bonds. More specifically, in our sample, Table 2 and Table 3 imply that the ratio between CDS spread to credit spread is only about $51 \%$ for 5 -year Baa rated bonds, a much lower number compared to $74 \%$ reported in Longstaff, Mithal, and Neis 
(2005). ${ }^{32}$ A lower targeted CDS spread implies a smaller default component, which leads to a calibrated model with a relatively higher liquidity component.

\subsubsection{The change of credit spreads over aggregate states}

This subsection addresses a long-standing question that has interested empirical researchers, e.g., Dick-Nielsen, Feldhütter, and Lando (2012) and Friewald, Jankowitsch, and Subrahmanyam (2012): How much of the soaring credit spread when the economy switches from boom to recession is due to increased credit risk, and how much is due to worsened secondary market liquidity? Our default-liquidity decomposition in (18) acknowledges that both liquidity and default risks for corporate bonds are endogenous and may affect each other. Given this feature, structural answers that rely on well-accepted economic structures are more appropriate than the reduced-form approaches.

We take the difference of credit spreads across two aggregate states for each rating class; results are reported in Panel $\mathrm{B}$ of Table 4 and graphically in Panel $\mathrm{C}$ of Figure 3. We observe that increased default risks constitute a large fraction of the jump in credit spreads. The pure liquidity component is also quantitatively significant in explaining the rise of credit spreads: even for Ba rated bonds, about $13 \%$ of the rise when entering recessions is due to the lower secondary market illiquidity in state $B$.

When the economy encounters a recession, the higher default risk lowers secondary market liquidity further, giving rise to a greater "default-driven liquidity" part. Since worse liquidity in state $B$ also pushes firms to default earlier, bond spreads rise because of a larger "liquiditydriven default" part. For low rated (say Ba) bonds, the "default-driven liquidity" channel (45\%) is more important than that of "liquidity-driven default" (10\%).

\section{[TABLE 4 ABOUT HERE]}

\footnotetext{
${ }^{32}$ In Longstaff, Mithal, and Neis (2005) whose sample period is from March 2001 to October 2002, the CDS spreads for Aaa/Aa rated bonds are about 59\% of their corresponding credit spreads; $60 \%$ for A, $74 \%$ for Baa, and $87 \%$ for Ba. In our data with a much longer sample period, these moments are $63 \%$ for Aaa/Aa, $52 \%$ for A, $51 \%$ for Baa, and $68 \%$ for B.
} 


\subsubsection{Default-liquidity decomposition in time-series}

Finally, we apply the default-liquidity decomposition scheme in Section 5.1 to the time series of credit spreads. For a given credit rating, we use the observed leverage distribution for firms within this rating each quarter to compute the average credit spread and its four components in equation (18). We treat the NBER expansions and recessions as states $G$ and $B$ in our model, respectively. One caveat of this assumption is that the model treats the severity of the 2001 recession and the 2008-09 recession as the same (we have excluded 2008Q4 and 2009Q1 in this study so far), even though the latter was arguably more severe in reality.

Figure 5 plots the time-series decomposition of credit spreads for Baa and B-rated bonds. To highlight the relative importance of the two interaction terms, in the left panels we plot the pure default spreads together with the liquidity-driven default spreads, while in the right panels we plot the pure liquidity spreads and the default-driven liquidity spreads.

The four components of the credit spreads are driven by both the time series variation in the leverage distribution and the aggregate state. Relative to Table 4, Figure 5 illustrates the time series variation in the cross-sectional leverage distribution.

Let us first consider the default components. For both the Baa-rated and B-rated firms, the liquidity-driven default spreads have meaningful magnitudes, but they are significantly smaller than the pure default spreads. Not surprisingly, both default components rise in the two recessions in the sample. The model predicts that the pure default spread for Baa spreads is lower in 2008-09 than in 2001. In reality, the fact that the 2008-09 recession was more severe than the 2001 recession (especially the financial crisis period from late 2008 to early 2009, which is marked in dark grey in the plots) drives the credit spreads higher in the 2008-09 recession.

Moving on to liquidity components, we observe that by definition the pure liquidity parts only depend on the aggregate state and are identical across ratings. In contrast, the default-driven liquidity spreads show significant variation over time and across ratings. For Baa-rated bonds, the default-driven liquidity spreads have similar magnitude as the pure 
Figure 5: Time-series Structural Decomposition of Credit Spreads for Baa and B-rated Firms. For each firm-quarter observation, we locate the corresponding cashflow level $y$ that delivers the observed quasi market leverage in Compustat (excluding financial and utility firms) and perform the structural liquidity-default decomposition for a 5-year bond following the procedure discussed in Section 4.4.1. For a given credit rating (Baa or B), we average across firms to obtain liquidity-default components for each quarter from 1994 to 2012. Recessions are highlighted in grey area. For completeness, we also calculate the model implied decomposition results for the crisis period from 2008Q4 to 2009Q1 in dark grey area (which is excluded from our study).
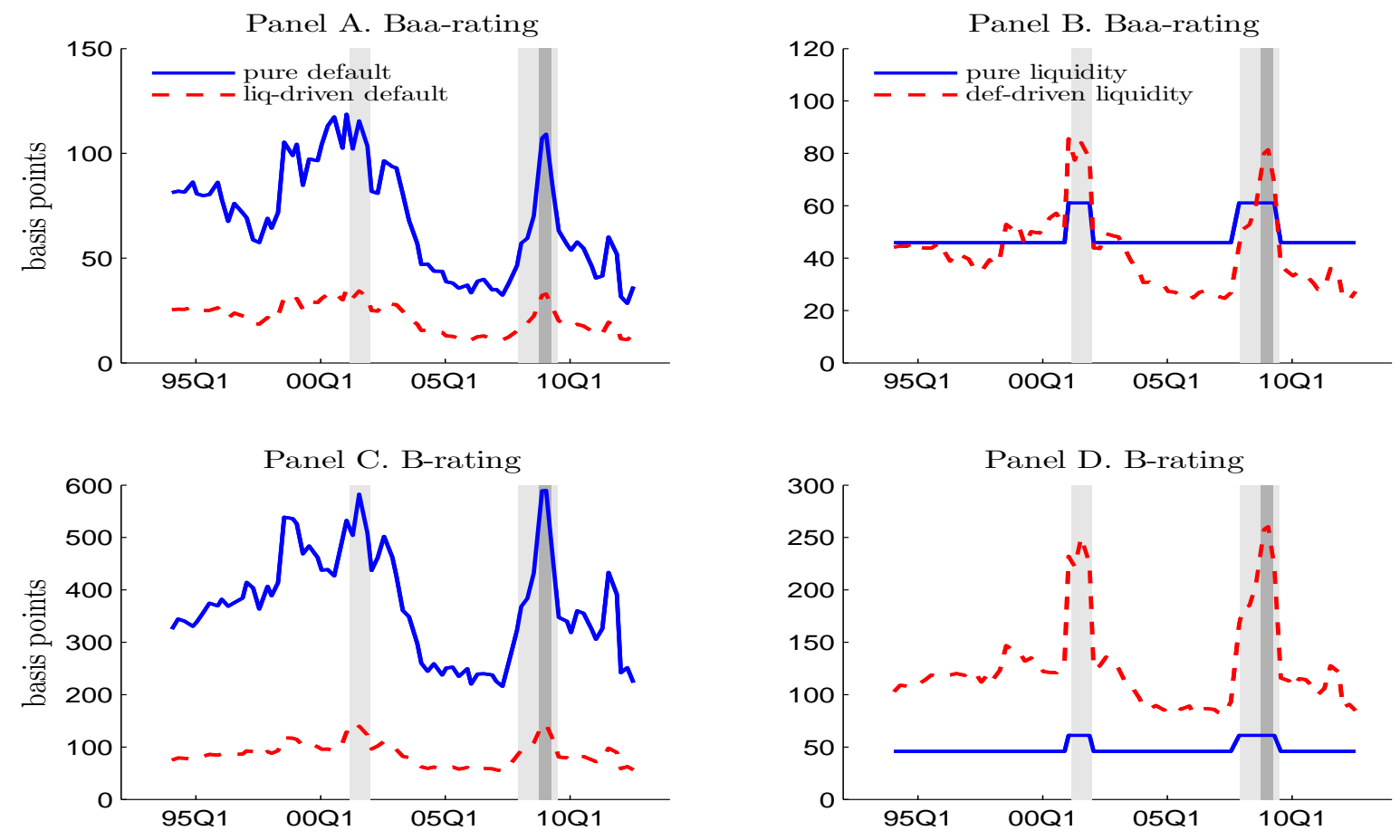

liquidity spreads on average, but the interaction term accounts for a larger fraction of the liquidity spreads in recessions. For B-rated bonds, the default-driven liquidity spreads account for the majority of the liquidity spreads, especially in recessions. 


\subsection{Applications}

\subsubsection{Implications on Evaluating Liquidity Provision Policy}

Our decomposition and its quantitative results are informative for evaluating the effect of policies that target lowering the borrowing cost of corporations in recession by injecting liquidity into the secondary market. As argued before, a full analysis of the effectiveness of such a policy must take account of how firms' default policies respond to liquidity conditions and how liquidity conditions respond to the default risks. These endogenous forces are what our model is aiming to capture.

Suppose that the government is committed to launching certain liquidity enhancing programs (e.g., Term Auction Facilities or discount window loans) whenever the economy falls into a recession, envisioning that the improved funding environment for financial intermediaries alleviates the worsening liquidity in the secondary bond market. Suppose that the policy is effective in making the secondary market in state $B$ as liquid as that of state $G$ in terms of the characteristic liquidity parameters. More precisely, the policy helps increase the meeting intensity between $L$ investors and dealers in state $B$, so that $\lambda_{B}$ rises from 20 to $\lambda_{G}=50$; and reduce the state $B$ holding cost parameter $\chi_{B}$ from 0.17 to $\chi_{G}=0.12$.

In Table 5 we take the same cash flow distribution for each rating class and aggregate state as in Table 4, and calculate the credit spreads with and without the state- $B$ liquidity provision policy on this fixed cash flow distribution. We find that a state- $B$ liquidity provision policy lowers state- $B$ credit spreads by about 40 (112) bps for Aaa/Aa (Ba) rated bonds, which is about $67 \%(32 \%)$ of the corresponding credit spreads. Moreover, given the dynamic nature of our model, the state- $B$-only liquidity provision affects firms' borrowing costs in state $G$ : the state- $G$ credit spreads for Aaa/Aa (Ba) rated bonds go down by 18 (46) bps, or about $33 \%(16 \%)$ of the corresponding credit spreads.

Our structural decomposition further allows us to investigate the underlying driving

force for the effectiveness of this liquidity provision policy. By definition, the "pure default" component remains unchanged given any policy that only affects the secondary market 
liquidity. ${ }^{33}$ In Table 5, we observe that the pure-liquidity component accounts for above $56 \%$ $(63 \%)$ of the drop in spread for Aaa/Aa rated bonds in state $G$ (state $B$ ). However, the quantitative importance of the pure-liquidity component goes down significantly when we walk down the rating spectrum: for Ba rated bonds, it only accounts for about $22 \%$ of the decrease in the credit spread.

The market-wide liquidity provision not only reduces investors' required compensation for bearing liquidity risk, but also alleviates some default risk faced by bond investors. A better functioning financial market helps mitigate a firm's rollover risk and thus relaxes its default risk - this force is captured by the "liquidity-driven default" part. This is an quantitatively important channel: it accounts for around 30\% of credit spread change in Aaa/Aa rated bonds, and goes up to $62 \%$ for lower Ba rated bonds.

Given that the hypothetical policy was limited to only improving secondary market liquidity, the channel of "default-driven liquidity" is more intriguing, which only exists in our model with endogenous liquidity featuring a positive feedback loop between corporate default and secondary market liquidity. Not surprisingly, the contribution through "default-driven liquidity" is smaller but not negligible. This interaction component can be quantitatively significant at about $10 \% \sim 17 \%$ for risky bonds.

\section{[TABLE 5 ABOUT HERE]}

\subsubsection{Implications on accounting recognitions of credit-related losses}

The interaction between liquidity and default as documented above has important implications for the ongoing debate regarding how accounting standards should recognize credit losses on financial assets. The interesting interplay between liquidity and default and their respective accounting recognitions has been illustrated in the collapse of Asset-Backed-Securities market during the second half of 2007. As Acharya, Schnabl, and Suarez (2013) document, because market participants are forward-looking, the liquidity problems (i.e., these conduits cannot

\footnotetext{
${ }^{33}$ The "pure default" component is defined by Leland and Toft (1996) which is independent of the secondary market liquidity.
} 
roll over their short-term financing) occur before the actual credit-related losses (assets in

the conduit start experiencing default). In a news release by Financial Accounting Standards Board (FASB) on 12/20/2013, the FASB Chairman Leslie F. Seidman noted that "the global financial crisis highlighted the need for improvements in the accounting for credit losses for loans and other debt instruments held as investment ... the FASB's proposed model would require more timely recognition of expected credit losses." However, there is no mentioning of the "liquidity" of these debt instrument at all. Our model not only suggests that (il)liquidity can affect the credit losses for these debt instruments, but more importantly offers a framework on how to evaluate the expected credit losses while taking into account the liquidity information.

\section{Concluding Remarks}

We build an over-the-counter search friction into a structural model of corporate bonds. In the model, firms default decisions interact with time varying macroeconomic and secondary market liquidity conditions. We calibrate the model to historical moments of default probability, bond yields and empirical measures of liquidity. The model is able to match the conditional observed credit spreads for corporate bonds across different rating classes and aggregate states, as well as various measures of non-default component studied in the previous literature. We propose a structural decomposition that captures the interaction of liquidity and default risks of corporate bonds over the business cycle and use this framework to evaluate the effects of liquidity provision policies during recessions. Our results identify quantitatively important economic forces that were previously overlooked in empirical researches on corporate bonds.

To focus on the interaction of liquidity and default, our model is cast in a partial equilibrium. Nevertheless, we believe these interactions have profound macroeconomic real impact, and the recent progress of general equilibrium models with credit risk (e.g., Gomes and Schmid (2010)) is the path for future research. 


\section{References}

Acharya, V. V., P. Schnabl, and G. Suarez, 2013, "Securitization without risk transfer," Journal of Financial Economics, 107, 515-536.

Bai, J., and P. Collin-Dufresne, 2012, "The CDS-Bond Basis During the Financial Crisis of 2007-2009," Working Paper.

Bao, J., J. Pan, and J. Wang, 2011, "The illiquidity of corporate bonds," The Journal of Finance, 66, 911-946.

Berk, J., and R. Green, 2004, "Mutual Fund Flows and Performance in Rational Markets," Journal of Political Economy, 112, 1269-1295.

Bhamra, H., L. Kuehn, and I. Strebulaev, 2010, "The levered equity risk premium and credit spreads: A unified framework," Review of Financial Studies, 23, 645-703.

BIS, 2010, The role of margin requirements and haircuts in procyclicality, Bank for International Settlements.

Bongaerts, D., F. De Jong, and J. Driessen, 2011, "Derivative pricing with liquidity risk: Theory and evidence from the credit default swap market," Journal of Finance, 66, 203-240.

Chen, H., 2010, "Macroeconomic conditions and the puzzles of credit spreads and capital structure," The Journal of Finance, 65, 2171-2212.

Chen, H., Y. Xu, and J. Yang, 2012, "Systematic Risk, Debt Maturity, and the Term Structure of Credit Spreads," Discussion paper, National Bureau of Economic Research.

Chen, L., P. Collin-Dufresne, and R. S. Goldstein, 2009, "On the Relation Between the Credit Spread Puzzle and the Equity Premium Puzzle," Review of Financial Studies, 22, $3367-3409$.

Cheng, I., and K. Milbradt, 2012, "The Hazards of Debt: Rollover Freezes, Incentives, and Bailouts," Review of Financial Studies, 25, 1070-1110. 
Collin-Dufresne, P., R. S. Goldstein, and S. J. Martin, 2001, "The Determinants of Credit Spread Changes," Journal of Finance, 56, 2177-2207.

David, A., 2008, "Inflation uncertainty, asset valuations, and the credit spreads puzzle," Review of Financial Studies, 21, 2487-2534.

Dick-Nielsen, J., 2009, "Liquidity Biases in TRACE," Journal of Fixed Income, 19, 43-55.

Dick-Nielsen, J., P. Feldhütter, and D. Lando, 2012, "Corporate bond liquidity before and after the onset of the subprime crisis," Journal of Financial Economics, 103, 471-492.

Duffie, D., 1996, "Special Repo Rates," Journal of Finance, 51, 493-526.

Duffie, D., N. Gârleanu, and L. Pedersen, 2005, "Over-the-Counter Markets," Econometrica, $73,1815-1847$.

Duffie, D., N. Gârleanu, and L. H. Pedersen, 2007, "Valuation in Over-the-Counter Markets," Review of Financial Studies, 20, 1865-1900.

Duffie, D., and K. J. Singleton, 1999, "Modeling Term Structures of Defaultable Bonds," Review of Financial Studies, 12, 687-720.

Edwards, A., L. Harris, and M. Piwowar, 2007, "Corporate bond market transaction costs and transparency," The Journal of Finance, 62, 1421-1451.

Feldhütter, P., 2012, "The same bond at different prices: identifying search frictions and selling pressures," Review of Financial Studies, 25, 1155-1206.

Friewald, N., R. Jankowitsch, and M. G. Subrahmanyam, 2012, "Illiquidity or credit deterioration: A study of liquidity in the US corporate bond market during financial crises," Journal of Financial Economics, 105, 18-36.

Gârleanu, N., and L. H. Pedersen, 2011, "Margin-Based Asset Pricing and the Law of One Price," Review of Financial Studies, 24, 1980-2022. 
Gilson, S. C., K. John, and L. H. P. Lang, 1990, "Troubled debt restructurings*1: An empirical study of private reorganization of firms in default," Journal of Financial Economics, 27, 315-353.

Gomes, J. F., and L. Schmid, 2010, "Equilibrium Credit Spreads and the Macroeconomy," working paper.

He, Z., and K. Milbradt, 2014, "Endogenous Liquidity and Defaultable Bonds," Forthcoming, Econometrica.

He, Z., and W. Xiong, 2012a, "Dynamic debt runs," Review of Financial Studies, 25, 17991843.

He, Z., and W. Xiong, 2012b, "Rollover risk and credit risk," The Journal of Finance, 67, 391-430.

Huang, J.-Z., and M. Huang, 2012, "How much of the Corporate-Treasury Yield Spread is Due to Credit Risk," Review of Asset Pricing Studies, 2, 153-202.

Ivashina, V., D. C. Smith, and B. Iverson, 2013, "The Ownership and Trading of Debt Claims in Chapter 11 Restructurings," Working Paper.

Jankowitsch, R., F. Nagler, and M. G. Subrahmanyam, 2013, "The Determinants of Recovery Rates in the US Corporate Bond Market," Working Paper.

Karakas, O., E. Hotchkiss, and P. Feldhutter, 2014, "The Impact of Creditor Control on Corporate Bond Pricing and Liquidity," working paper.

Krishnamurthy, A., 2002, "The bond/old-bond spread," Journal of Financial Economics, 66, $463-506$.

Leland, H., 1998, “Agency costs, risk management, and capital structure," Journal of Finance, 53, 1213-1243. 
Leland, H., and K. Toft, 1996, "Optimal capital structure, endogenous bankruptcy, and the term structure of credit spreads," The Journal of Finance, 51, 987-1019.

Liu, J., F. A. Longstaff, and R. E. Mandell, 2006, "The Market Price of Risk in Interest Rate Swaps: The Roles of Default and Liquidity Risks," The Journal of Business, 79, 2337-2360.

Longstaff, F., S. Mithal, and E. Neis, 2005, "Corporate yield spreads: Default risk or liquidity? New evidence from the credit default swap market," The Journal of Finance, 60, 2213-2253.

Longstaff, F. A., 2004, "The Flight-to-Liquidity Premium in U.S. Treasury Bond Prices," The Journal of Business, 77, 511-526.

Oehmke, M., and A. Zawadowski, 2013, "The anatomy of the CDS market," Working Paper.

Roll, R., 1984, "A simple implicit measure of the effective bid-ask spread in an efficient market," Journal of Finance, 39, 1127-39.

Suarez, G., E. Schroth, and L. Taylor, 2014, "Dynamic Debt Runs and Financial Fragility: Evidence from the 2007 ABCP Crisis," Journal of Financial Economics, 112, 164-189. 


\section{Appendix}

\section{A Holding Costs Microfoundation}

This section gives the details of the derivation of endogenous holding costs that depend on current bond value. The derivation also applies to other assets that are traded on an over-the-counter search market.

Suppose that investors can only borrow at the riskfree rate $r$ if the loan is collateralized; otherwise the borrowing rate is $r+\chi$ for all uncollateralized amounts. Suppose further that, when an agent is hit by a liquidity shock, he will need to raise an amount of cash that is large relative to his financial asset holdings. This assumption implies that the agent will borrow at the uncollateralized rate $r+\chi$ in addition to selling all of his liquid assets.

The agent can reduce the financing cost of uncollateralized borrowing by using the bond as collateral to raise an amount $(1-h(y)) P(y)$, where $h(y)$ is the haircut on the collateral and $P(y)=\frac{A(y)+B(y)}{2}$ is the midpoint bond price. Then, the ownership of the bond conveys a marginal value of $\chi(1-h(y)) P(y)$ per unit of time (equaling to the net savings on financing cost) until the time of sale. At the time of sale, which occurs with intensity $\lambda$, on top of the sale proceeds equal to the bid price $B(y)$, the bond conveys a marginal value of $\chi B(y)$ per unit of time perpetually, or $\frac{\chi B(y)}{r}$ in present value. Notice that that there is no haircut on the cash proceeds. Intuitively, a more risky collateral asset will face a larger haircut, which lowers its marginal value for an investor hit by liquidity shocks. This is the channel that generates the relative holding cost in our model.

We can now characterize value of the bond in terms of the utility of an investor, which can be different from the market value of the bond when the investor's marginal value of cash is above 1 .

$$
\begin{aligned}
& r V_{H}(y)=c+\mathcal{L} V_{H}(y)+\xi_{H L}\left[V_{L}(y)-V_{H}(y)\right] \\
& r V_{L}(y)=c+\chi(1-h(y)) P(y)+\mathcal{L} V_{L}(y)+\lambda\left[B(y)+\frac{\chi B(y)}{r}-V_{L}(y)\right]
\end{aligned}
$$

Suppose that with probability $\beta$, the investor can make a take-it-or-leave-it offer to the dealer, and with probability $(1-\beta)$ the dealer can make the offer the the investor. If the dealer gets to make the offer, his offering price will be such that $B(y)+\frac{\chi B(y)}{r}-V_{L}(y)=0$, or

$$
B_{d}(y)=\frac{r}{r+\chi} V_{L}(y)
$$

The dealer's outside option is 0 , and his valuation of the bond is simply $V_{H}(y)$, the price at which he can sell the bond on the secondary market to $H$-type investors. If the investor gets to make the offer, his offering price will be

$$
B_{i}(y)=V_{H}(y) .
$$

Thus, with probability $\beta$, a surplus of $\left[\left(1+\frac{\chi}{r}\right) V_{H}(y)-V_{L}(y)\right]$ accrues to the investor, and with probability $(1-\beta)$, zero surplus accrues to the investor. We can also see that cash has a Lagrange multiplier $1+\frac{\chi}{r}>1$ in the liquidity state $L$. 
Further, the mid-point bond price is

$$
P(y)=\frac{A(y)+B(y)}{2}=\frac{V_{H}(y)+(1-\beta) V_{H}(y)+\beta \frac{r}{r+\chi} V_{L}(y)}{2}=\left(1-\frac{\beta}{2}\right) V_{H}(y)+\frac{\beta}{2} B_{d}(y) .
$$

Multiply the $V_{L}$ equation (20) by $\frac{r}{r+\chi}$, we rewrite to get

$$
r B_{d}(y)=\frac{r}{r+\chi}[c+\chi(1-h(y)) P(y)]+\mathcal{L} B_{d}(y)+\lambda \beta\left[V_{H}(y)-B_{d}(y)\right]
$$

From (20) to (24), we have simply re-expressed the bond valuation in state $L$ from being in utility terms into dollar terms through the Lagrange multiplier, which allows us to express the effective holding cost in dollars. Specifically, we can rewrite the flow term in (24) as

$$
\frac{r}{r+\chi}[c+\chi(1-h(y)) P(y)]=c-\underbrace{\frac{\chi}{r+\chi}[c-r(1-h(y)) P(y)]}_{\text {holding cost }},
$$

where the second term can be interpreted as the holding cost. Under appropriate parameterization, this holding cost is increasing in the spread for uncollateralized financing $\chi$ and the haircut $h(y)$.

While we have left the haircut function $h(y)$ as exogenous, it is intuitive that it should become larger when the bond becomes more risky, which is when the bond price is lower. Consider the following functional form,

$$
h(y)=\frac{a_{0}}{P(y)}-a_{1} .
$$

By choosing $a_{0}=(N(r+\chi)-c) / r$ and $a_{1}=\chi / r$, we obtain the holding cost $h c(y)=\chi(N-P(y))$ as in equation (5). ${ }^{34}$

Given $N=107, \chi_{G}=12 \%, \chi_{B}=17 \%$ and other baseline calibrations, we find that modelimplied haircuts range from $10 \%$ to $25 \%$ depending on ratings. They are broadly consistent with BIS (2010) which gives a comprehensive survey conducted by the BIS Committee on the Global Financial System (including both Europe and US) for June 2007 and June 2009. The model implied haircuts are $9 \%$ for Aaa/Aa bonds, $10 \%$ for A, $12 \%$ for Baa, and 18\% for Ba. In BIS (2010), the average haircuts for non-rated counterparties are $6.7 \%$ for Aaa/Aa rated bonds, $12 \%$ for Baa, and $23 \%$ for high yield bonds.

\footnotetext{
${ }^{34}$ Clearly, we will need to pick the parameter values for $N$ and $\chi$ appropriately to keep the haircut between 0 and 1.
} 
Table 1: Baseline Parameters used in calibration. Unreported parameters are the tax rate of $\pi=0.35$, and bond face value $p=100$. Panel A reports pre-fixed parameters. Transition density $\zeta^{\mathbb{P}}$, jump risk premium $\exp (\kappa)$, risk price $\eta$, risk-free rate $r$, cash flow growth $\mu_{\mathbb{P}}$, primary bond market issuance cost $\kappa$, and inverse of debt maturity $m$ are similar to the literature (e.g., Chen, Xu, and Yang (2012)). Systematic volatility $\sigma_{m}$ is chosen to match equity volatility. Meeting intensities $\lambda_{s}$ are set so that selling holdings takes one week (2.5 weeks) in normal (recession) period. The liquidity shock intensity $\xi_{B}$ is set to match bond turnover in Bond-CDS sample in recession, and we set $\xi_{G}=\xi_{B}$. Investors' bargaining power $\beta$ is from Feldhütter (2012). State- and type- dependent recovery rates $\alpha_{l}^{s}$ 's are calculated using existing literature on credit risk models and observed bid-ask spreads of defaulted bonds. Panel B reports four calibrated parameters. The idiosyncratic volatility $\sigma_{f}$ is chosen to target the default probability of Baa firms. The holding cost parameters $N$ is set to target the Baa state- $G$ Bond-CDS spread, and $\chi_{s}$ 's are chosen to target the investment grade bid-ask spreads.

\begin{tabular}{|c|c|c|c|c|}
\hline Symbol & Description & State G & State B & Justification / Target \\
\hline \multicolumn{5}{|c|}{ A. Pre-fixed parameters } \\
\hline$\zeta^{\mathbb{P}}$ & Transition density & 0.1 & 0.5 & literature; Section 4.1.1 \\
\hline $\exp (\kappa)$ & Jump risk premium & 2.0 & 0.5 & literature; Section 4.1 .1 \\
\hline$\eta$ & Risk price & 0.165 & 0.255 & literature; Section 4.1 .1 \\
\hline$r$ & Risk free rate & \multicolumn{2}{|c|}{0.05} & historical data; Section 4.1 .1 \\
\hline$\mu_{\mathbb{P}}$ & Cash flow growth & 0.045 & 0.015 & literature; Section 4.1.1 \\
\hline$\sigma_{m}$ & Systematic vol & 0.1 & 0.11 & equity vol; Section 4.1 .1 \\
\hline$\omega$ & Primary market issuance cost & \multicolumn{2}{|c|}{0.01} & literature; Section 4.1.1 \\
\hline$m$ & Average maturity intensity & \multicolumn{2}{|c|}{0.2} & literature; Section 4.1 .1 \\
\hline$\lambda$ & Meeting intensity & 50 & 20 & anecdotal evidence; Section 4.1 .2 \\
\hline$\xi$ & Liquidity shock intensity & \multicolumn{2}{|c|}{2} & turnover in $B$, Bond-CDS sample; Section 4.1 .2 \\
\hline$\beta$ & Investor's bargaining power & \multicolumn{2}{|c|}{0.05} & literature; Section 4.1 .2 \\
\hline$\alpha_{H}$ & Recovery rate of $H$ type & $58.71 \%$ & $32.56 \%$ & literature; Section 4.1.3 \\
\hline$\alpha_{L}$ & Recovery rate of $L$ type & $57.49 \%$ & $30.50 \%$ & literature; Section 4.1 .3 \\
\hline \multicolumn{5}{|c|}{ B. Calibrated parameters } \\
\hline$\sigma_{f}$ & Idiosyncratic vol & \multicolumn{2}{|c|}{0.225} & Baa default probability; Section 4.1 .1 \\
\hline$N$ & Holding cost intercept & \multicolumn{2}{|c|}{107} & Baa Bond-CDS spread in $G$; Section 4.1.2 \\
\hline$\chi$ & Holding cost slope & 0.12 & 0.17 & Investment bid-ask spread; Section 4.1 .2 \\
\hline
\end{tabular}


Table 2: Default probabilities and credit spreads across credit ratings. Default probabilities are cumulative default probabilities over 1920-2011 from Moody's investors service (2012), and credit spreads are from FISD and TRACE transaction data over 1994-2010. We report the time series mean, with the standard deviation (reported underneath) being calculated using Newey-West procedure with 15 lags. The standard deviation of default probabilities are calculated based on the sample post 1970's due to data availability issue. On model part, we first calculate the quasi market leverage for Compustat firms (excluding financial and utility firms) for each rating over 1994-2010 (excluding the crisis quarters 2008Q4 and 2009Q1), then match observed quasi market leverage by locating the corresponding cash flow level $y$. We calculate the average of model-implied credit spreads and Bond-CDS spreads across these firm-quarter observations. This procedure implies that our model-implied leverages exactly match their empirical counterparts. The row of " $h c_{s}$ " gives the implied moments under the assumption that holding costs depend on aggregate state only (i.e., not $h c_{s}(P)$, and we calibrate $h c_{G}=1.78$ and $h c_{B}=3.20$ to match investment-grade bid-ask spreads). The row of $\chi=0$ gives the model implied moments when there is no liquidity frictions under our baseline parameters.

\begin{tabular}{|c|c|c|c|c|c|c|c|c|}
\hline \multirow{7}{*}{$\begin{array}{c}\text { data } \\
\text { model } \\
\chi=0 \\
h c_{s}\end{array}$} & \multicolumn{4}{|c|}{ Maturity $=5$ years } & \multicolumn{4}{|c|}{ Maturity $=10$ years } \\
\hline & $\mathrm{Aaa} / \mathrm{Aa}$ & A & Baa & $\mathrm{Ba}$ & $\mathrm{Aaa} / \mathrm{Aa}$ & $\mathrm{A}$ & Baa & $\mathrm{Ba}$ \\
\hline & \multicolumn{8}{|c|}{ Panel A. Default probability (\%) } \\
\hline & 0.7 & 1.3 & 3.1 & 9.8 & 2.1 & 3.4 & 7.0 & 19.0 \\
\hline & 0.5 & 1.5 & 3.7 & 9.9 & 2.5 & 5.8 & 10.9 & 20.0 \\
\hline & 0.4 & 1.0 & 2.8 & 8.2 & 2.0 & 4.7 & 9.3 & 17.7 \\
\hline & 0.4 & 1.2 & 3.3 & 8.9 & 2.2 & 5.2 & 10.1 & 18.8 \\
\hline & \multicolumn{8}{|c|}{ Panel B. Credit spreads (bps) } \\
\hline & \multicolumn{8}{|c|}{ State $G$} \\
\hline data & 55.7 & 85.7 & 149 & 315 & 61.2 & 90.2 & 150 & 303 \\
\hline & $(3.7)$ & $(6.6)$ & $(15.5)$ & $(33.8)$ & $(4.4)$ & $(6.3)$ & (12.8) & $(22.7)$ \\
\hline model & 72.9 & 103 & 170 & 341 & 108 & 193 & 305 & 490 \\
\hline$\chi=0$ & 10.1 & 26.5 & 68.8 & 194 & 26.5 & 61.1 & 119 & 234 \\
\hline \multirow[t]{2}{*}{$h c_{s}$} & 130 & 150 & 196 & 328 & 155 & 203 & 270 & 390 \\
\hline & \multicolumn{8}{|c|}{ State $B$} \\
\hline data & 107 & 171 & 275 & 542 & 106 & 159 & 262 & 454 \\
\hline & $(5.8)$ & (10.5) & $(23.9)$ & $(29.8)$ & $(6.7)$ & (13.8) & $(29.3)$ & $(44.4)$ \\
\hline model & 99 & 148 & 243 & 459 & 146 & 259 & 409 & 642 \\
\hline$\chi=0$ & 12.9 & 33.8 & 84.0 & 221 & 29.4 & 70.0 & 133 & 255 \\
\hline$h c_{s}$ & 187 & 216 & 277 & 430 & 195 & 253 & 333 & 466 \\
\hline
\end{tabular}


Table 3: Bond-CDS spreads and bid-ask spreads across credit ratings. The sample in Panel A consists of firms with both 5-year and 10-year bonds outstanding over 2005 to 2012. We report the time series mean (excluding crisis period from October 2008 to March 2009), with the standard deviation (reported underneath) being calculated using Newey-West procedure with 15 lags. On the model side, we calculate the quasi market leverage for Compustat firms (excluding financial and utility firms) for each rating classes. We match the observed quasi market leverage by locating the corresponding cash flow level $y$, and calculate the time series average of model-implied credit spreads and Bond-CDS spreads across these firm-quarter observations (excluding the crisis quarters 2008Q4 and 2009Q1). The row of " $h c_{s}$ " gives the implied moments under the assumption that holding costs depend on aggregate state only (i.e., not $h c_{s}(P)$, and we calibrate $h c_{G}=1.78$ and $h c_{B}=3.20$ to match investment-grade bid-ask spreads). The row of $\chi=0$ gives the model implied moments when there is no liquidity frictions under our baseline parameters. In Panel B, the normal time bid-ask spreads are taken from Edwards, Harris, and Piwowar (2007) for median sized trades. The recession time numbers are normal time numbers multiplied by the ratio of bid-ask spread implied by Roll's measure of illiquidity (following Bao, Pan, and Wang (2011)) in recession time to normal time. The model counterpart is computed for a bond with time to maturity of 8 years, which is the mean time-to-maturity of frequently traded bonds (where we can compute a Roll (1984) measure) in the TRACE sample.

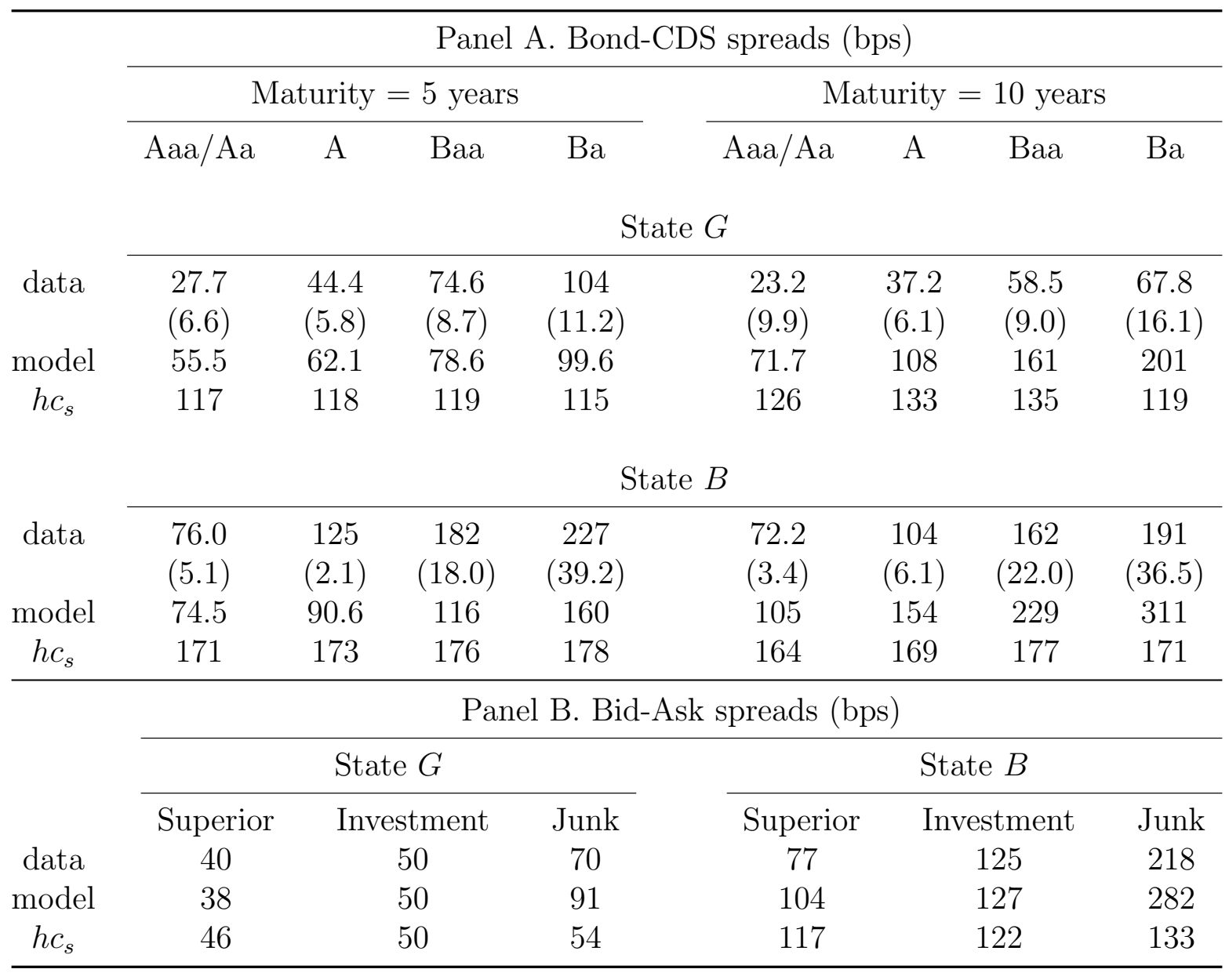


Table 4: Structural Liquidity-Default Decomposition for 5-Year Bonds Across Ratings. For each firm-quarter observation, we locate the corresponding cashflow level $y$ that delivers the observed quasi market leverage in Compustat. We then perform the structural liquiditydefault decomposition for a 5-year bond following Section 4.4.1, given rating and aggregate state, and then aggregate over the leverage distribution. Panel A reports the liquidity-default decompositions for the level of credit spread; panel B reports the liquidity-default decomposition for the change of credit spread between state $G$ and state $B$.

\begin{tabular}{|c|c|c|c|c|c|c|}
\hline \multirow{2}{*}{ Rating } & \multirow{2}{*}{ State } & \multirow{2}{*}{$\begin{array}{l}\text { Credit } \\
\text { Spread }\end{array}$} & \multicolumn{4}{|c|}{ Default-Liquidity Decomposition } \\
\hline & & & Pure Def & Liq $\rightarrow$ Def & Pure Liq & Def $\rightarrow$ Liq \\
\hline \multirow{5}{*}{$\mathrm{Aaa} / \mathrm{Aa}$} & \multicolumn{6}{|c|}{ Panel A: Explaining Credit Spread Levels } \\
\hline & $G(\mathrm{bps})$ & 72.9 & 9.7 & 2.8 & 45.9 & 14.4 \\
\hline & $(\%)$ & 100 & 13 & 4 & 63 & 20 \\
\hline & $B$ (bps) & 99.1 & 13.8 & 4.1 & 61.1 & 20.1 \\
\hline & $(\%)$ & 100 & 14 & 4 & 62 & 20 \\
\hline \multirow{4}{*}{$\mathrm{A}$} & $G(\mathrm{bps})$ & 103 & 25.8 & 8.9 & 45.9 & 22.0 \\
\hline & $(\%)$ & 100 & 25 & 9 & 45 & 21 \\
\hline & $B(\mathrm{bps})$ & 148 & 36.1 & 12.2 & 61.1 & 38.3 \\
\hline & $(\%)$ & 100 & 24 & 8 & 41 & 26 \\
\hline \multirow{4}{*}{ Baa } & $G(\mathrm{bps})$ & 170 & 65.5 & 20.5 & 45.9 & 37.9 \\
\hline & $(\%)$ & 100 & 39 & 12 & 27 & 22 \\
\hline & $B$ (bps) & 243 & 86.9 & 26.7 & 61.1 & 68.5 \\
\hline & $(\%)$ & 100 & 36 & 11 & 25 & 28 \\
\hline \multirow{4}{*}{$\mathrm{Ba}$} & $G(\mathrm{bps})$ & 341 & 178 & 45.3 & 45.9 & 71.9 \\
\hline & $(\%)$ & 100 & 52 & 13 & 13 & 21 \\
\hline & $B(\mathrm{bps})$ & 459 & 215 & 57.5 & 61 & 124.7 \\
\hline & $(\%)$ & 100 & 47 & 13 & 13 & 27 \\
\hline
\end{tabular}

Panel B: Explaining Credit Spread Changes

\begin{tabular}{ccccccc}
\cline { 2 - 6 } Aaa/Aa & $\begin{array}{c}G \rightarrow B(\mathrm{bps}) \\
(\%)\end{array}$ & 26.2 & 4.1 & 1.3 & 15.2 & 5.6 \\
& 100 & 16 & 5 & 58 & 22 \\
\cline { 2 - 7 } $\mathrm{A}$ & $\begin{array}{c}G \rightarrow B(\mathrm{bps}) \\
(\%)\end{array}$ & 45.0 & 10.3 & 3.3 & 15.2 & 16.3 \\
& 100 & 23 & 7 & 34 & 36 \\
\cline { 2 - 7 } Baa & $\begin{array}{c}G \rightarrow B(\mathrm{bps}) \\
(\%)\end{array}$ & 73.5 & 21.5 & 6.2 & 15.2 & 30.6 \\
& 100 & 29 & 8 & 21 & 42 \\
$\mathrm{nyyyyyy}$ Ba & $G \rightarrow B(\mathrm{bps})$ & 118 & 37.6 & 12.2 & 15.2 & 52.8 \\
& $(\%)$ & 100 & 32 & 10 & 13 & 45 \\
\hline
\end{tabular}


Table 5: Effect of Liquidity Provision Policy on 5-Year Bonds Across Ratings. We consider a policy experiment that improves the liquidity environment $(\chi, \lambda)$ in the $\mathrm{B}$ state to be as good as G state. We fix the distribution of cashflow levels $y$ at the values that deliver the observed market leverage distribution in Compustat (excluding financial and utility firms) for the corresponding state in our baseline calibration. We then report the average credit spreads under the policy for both $\mathrm{G}$ and B states together with credit spread without policy. We perform the structural liquidity-default decomposition to examine the channels that are responsible for the reduced borrowing cost. We report the percentage contribution of each component to the credit spread change. Note that the pure default component remains unchanged regardless of policy as it is based on a perfectly liquid world and only liquidity parameters are influenced by policy.

\begin{tabular}{|c|c|c|c|c|c|c|}
\hline \multirow[b]{2}{*}{ Rating } & \multirow[b]{2}{*}{ State } & \multicolumn{2}{|c|}{ Credit Spread (rf) } & \multicolumn{3}{|c|}{ Contribution of Each Component } \\
\hline & & $\begin{array}{l}\mathrm{w} / \mathrm{o} . \\
\text { policy }\end{array}$ & $\begin{array}{c}\text { w. } \\
\text { policy }\end{array}$ & $\frac{\mathrm{LIQ} \rightarrow \mathrm{DEF}}{(\%)}$ & $\frac{\text { pure LIQ }}{(\%)}$ & $\frac{\mathrm{DEF} \rightarrow \mathrm{LIQ}}{(\%)}$ \\
\hline \multirow{2}{*}{ Aaа/Aa } & $G$ & 72.9 & 54.7 & 30 & 56 & 14 \\
\hline & $B$ & 99.1 & 59.2 & 30 & 64 & 6 \\
\hline \multirow{2}{*}{ A } & $G$ & 102.7 & 78.4 & 45 & 42 & 13 \\
\hline & $B$ & 148 & 92.6 & 46 & 46 & 8 \\
\hline \multirow{2}{*}{ Baa } & $G$ & 170 & 136.3 & 52 & 30 & 18 \\
\hline & $B$ & 243 & 166 & 56 & 33 & 11 \\
\hline \multirow{2}{*}{$\mathrm{Ba}$} & $G$ & 341 & 295 & 62 & 22 & 16 \\
\hline & $B$ & 459 & 347 & 67 & 23 & 11 \\
\hline
\end{tabular}

